\title{
GOVERNMENT BOND \\ RISK PREMIA AND \\ THE CYCLICALITY OF FISCAL POLICY
}

by Kai Christoffel, Ivan Jaccard and Juha Kilponen 


\title{
GOVERNMENT BOND RISK PREMIA AND THE CYCLICALITY OF FISCAL POLICY'
}

\author{
by Kai Christoffel ${ }^{2}$, Ivan Jaccard ${ }^{2}$ \\ and Juha Kilponen ${ }^{3}$
}

NOTE: This Working Paper should not be reported as representing the views of the European Central Bank (ECB).

The views expressed are those of the authors and do not necessarily reflect those of the ECB.

This paper can be downloaded without charge from http://www.ecb.europa.eu or from the Social Science Research Network electronic library at http://ssrn.com/abstract_id $=1969854$.

\footnotetext{
I We thank Wouter den Haan, Christian Matthes, Jordi Galí and seminar participants at the ECB, the Goethe-University Frankfurt and University of Bonn for helpful comments. Views expressed in this paper are those of the authors and do not necessarily reflect the views of the European Central Bank, the Bank of Finland, or the European Financial Stability Facility.

2 European Central Bank, Kaiserstrasse 29, 603II Frankfurt am Main, Germany; e-mails: kai.christoffel@ecb.europa.eu and ivan.jaccard@ecb.europa.eu 3 Bank of Finland, Rauhankatu 19, Fl-00I0I Helsinki, Finland; e-mail: juha.kilponen@bof.fi; and European Financial 
(C) European Central Bank, 2011

\section{Address}

Kaiserstrasse 29

60311 Frankfurt am Main, Germany

Postal address

Postfach 160319

60066 Frankfurt am Main, Germany

Telephone

+496913440

Internet

http://www.ecb.europa.eu

Fax

+496913446000

All rights reserved.

Any reproduction, publication and reprint in the form of a different publication, whether printed or produced electronically, in whole or in part, is permitted only with the explicit written authorisation of the ECB or the authors.

Information on all of the papers published in the ECB Working Paper Series can be found on the ECB's website, http://www. ecb.europa.eu/pub/scientific/wps/date/ html/index.en.html

ISSN 1725-2806 (online) 


\section{CONTENTS}

Abstract

Non-technical summary

1 Introduction

2 The model

2.1 Households

2.2 Specification of utility

2.3 Firms

2.4 Pricing of long-term bonds and risk premium

2.5 Government

2.6 Market clearing

3 Estimation

3.1 Calibrated parameters 20

3.2 Estimation results

4 Fiscal policy, monetary policy, and the bond risk premium

4.1 Results and accuracy test

4.2 What drives the risk premium?

4.3 The role of fiscal and monetary policy

5 Conclusions

References

Tables and figures 


\begin{abstract}
We introduce a specification of habit formation featuring non-separability between consumption and leisure into an otherwise standard New Keynesian model. The model can be estimated with standard Bayesian techniques and the bond pricing implications are evaluated using higher-order approximations. The model is able to reproduce a sizeable risk premium on long-term bonds and the cyclicality of fiscal policy has an impact on the bond premium that is quantitatively important. Technology, government spending, and mark-up shocks are the main drivers of the time-variation in bond premia.
\end{abstract}

KEYWORDS: DSGE models, fiscal policy, bond risk premium, monetary policy.

JEL Classification Numbers: E5, E6, G1. 


\section{Non-technical summary}

At the heart of the nexus between fiscal policy and financial stability lies the question of the impact of fiscal policies on government risk premia. However, standard macroeconomic models are not very well suited to shed light on the interactions between fiscal rules, monetary policy, and risk premia.

In order to study the bond pricing implications of fiscal policy, we start by introducing a specific assumption concerning household's preferences into a standard New Keynesian model. Our first main finding is that this modification improves the model's ability to jointly explain macroeconomic and financial market facts. In particular, when simulated using higher-order approximations, the model estimated with macroeconomic and fiscal aggregates is able to generate a sizeable, and time-varying, bond premium. This relative success opens the door for studying the interaction between government bond risk premia and fiscal policy.

Turning to policy issues, our main finding is that modest changes in the cyclicality of fiscal spending can have a significant impact on the bond risk premium. Compared to the estimated model, increasing the degree of pro-cyclicality leads to an increase in the bond premium that can be quite large. Overall, the sensitivity analysis that is performed suggests that adopting counter-cyclical policy rules could help to contain risk premia during periods of high risk aversion.

Adopting pro-cyclical fiscal policy rules also has a destabilizing effect on the business cycle. Increasing fiscal expenditures in boom periods creates an additional demand that leads to stronger price pressures, higher interest rate volatility, and a higher bond premium. The higher volatility of inflation can be offset by the central bank by becoming more responsive to changes in inflation. While this policy succeeds in containing inflationary pressures, it comes at the cost of increasing interest rate volatility which, in turn, raises the cost of government debt financing. Pro-cyclical fiscal policy therefore creates an unfavorable trade-off between macroeconomic stabilization and government bond risk premia. 


\section{Introduction}

At the heart of the nexus between fiscal policy and financial stability lies the question of the impact of fiscal policies on government risk premia. However, macroeconomic models are not very well suited to shed light on the interactions between fiscal rules, monetary policy, and government bond risk premia. The risk premium produced by standard macroeconomic models such as Christiano, Eichenbaum, and Evans (2005) or Smets and Wouters (2007) is too small and not volatile enough (Hordahl, Tristani, and Vestin, 2008; Rudebusch and Swanson, 2008; Rudebusch, 2010). Furthermore, appending a term structure to these models finds only limited support in the data (De Graeve, Emiris, and Wouters, 2009). At the same time, standard asset pricing models which are targeted on the reproduction of risk premia typically fall short of important dimensions such as plausible inflation dynamics, labor markets, or a meaningful fiscal sector. As explained by den Haan (1995), the key problem of standard macroeconomic models is to generate a co-movement which implies that bond prices are low in states where marginal utility, or "hunger" is high. ${ }^{1}$

The co-movement between macroeconomic aggregates and financial variables implied by changes in government spending is particularly difficult to reconcile with the sizeable bond premium observed in the data. According to the textbook IS-LM model, an increase in government spending should lead to an increase in interest rates, inflation and consumption. In most asset pricing models, however, a rise in interest rates and inflation leads to a decline in bond prices. If bond prices are low in good times, when marginal utility is low and consumption is high, long-term bonds provide a hedge against unforeseen movements in consumption and the bond premium could even be negative (Backus, Gregory, and Zin, 1989). The co-movement implied by changes in fiscal policy should therefore reduce the compensation required to induce investors to hold government debt and contribute to worsen the bond premium puzzle.

\footnotetext{
${ }^{1}$ To generate a sizeable bond premium the model is not only required to get the sign of the co-movement right but also to produce enough volatility to match the size of the bond premium. Producing this volatility has also proven to be challenging.
} 
We start by augmenting a version of the New Neoclassical Synthesis (NNS) model (Goodfriend and King, 1997; Woodford, 2003; Galí, 2008) featuring an explicit fiscal block, with habit formation in the composite of consumption and leisure (Jaccard, 2010). Our first main finding is that the model can generate a sizeable and time-varying bond premium. This relative success opens the door for studying the interaction between the bond premium and fiscal policy. Counterfactual policy experiments are then conducted to study how changes in the cyclicality of fiscal policy affect the size of the bond risk premium.

The main distinguishing feature of this preference specification is to link marginal utility to movements in the composite of consumption and leisure (as opposed to a standard specification that only depends on consumption). In a model where this specification is combined with sticky prices, the key is that the response of hours worked can have a first-order impact on the dynamics of marginal utility. If an increase in government spending leads to an increase in hours worked that is sufficiently large and persistent, the fiscal expansion could lead to a decline in the composite good even if consumption increases. Since a decline in the composite good raises marginal utility, this mechanism implies that changes in fiscal policy could potentially generate the negative co-movement between marginal utility and bond prices that is needed to increase the bond premium. Determining whether this effect is quantitatively significant however remains an empirical question.

To assess the empirical relevance, the model is estimated with Bayesian likelihoodbased techniques. From an empirical perspective, the main advantage of habit formation (Abel, 1990; Constantinides, 1990; Jermann, 1998; Campbell and Cochrane, 1999; Boldrin, Christiano, and Fisher, 2001) is that standard linearization techniques can be employed. Consequently, the approach set out by An and Schorfheide (2007), and Smets and Wouters (2007) can be followed to estimate the key structural parameters based on a first-order approximation. ${ }^{2}$ To ensure that the size and the dynamics of

\footnotetext{
${ }^{2}$ To evaluate the bond pricing implications the model is simulated at posterior mode using higherorder approximations. Note that under Epstein-Zin preferences the structural parameters of the utility
} 
the bond premium are driven by the business cycle properties of the model economy, financial variables are not included into the set of observable variables. ${ }^{3}$

Our first main finding is that, when simulated using higher-order approximations, the model estimated with macroeconomic and fiscal aggregates is able to generate a sizeable, time-varying bond premium. Second, technology and government spending shocks are the main drivers of the time-variation in bond premia and, for the combination of estimated parameter that we obtain, changes in fiscal policy generate a negative co-movement between marginal utility and bond prices. ${ }^{4}$ Introducing fiscal policy into the analysis therefore contributes to the resolution of the bond premium puzzle. And as in the IS-LM model, expansionary fiscal policies lead to an increase in consumption, an empirical fact that is typically difficult to reproduce within this class of models (Galí, López Salido, and Vallés, 2007; Monacelli and Perotti, 2008). Third, we find that modest changes in the cyclicality of fiscal spending can have a significant impact on the bond risk premium. Compared to the estimated model, increasing the degree of pro-cyclicality leads to an increase in the bond premium that can be quite large. Overall, the sensitivity analysis that is performed suggests that adopting counter-cyclical policy rules could help to contain risk premia during periods of high risk aversion.

Adopting pro-cyclical fiscal policy rules also has a destabilizing effect on the business cycle, increasing the volatility of inflation and output, and the size of the risk premium. If fiscal authorities increase their expenditure in boom periods, the additional demand that is created leads to stronger price pressures, higher interest rate volatility and a higher bond premium. The higher volatility of inflation can be offset by the central bank by becoming more responsive to changes in inflation. While this policy succeeds in bringing down inflation volatility, it comes at the cost of increasing interest rate

function can not be estimated using standard techniques (van Binsbergen, Fernandez-Villaverde, Koijen, and Rubio-Ramirez, 2010).

${ }^{3}$ This empirical strategy also considerably reduces the number of degrees of freedom since a specific value for the bond premium will not explicitly be targeted.

${ }^{4}$ This negative co-movement is obtained for changes in both the systematic and the non-systematic components of fiscal policy. 
volatility. This increased volatility is then transmitted to the term premium via the term structure of interest rates and raises the cost of government debt financing. Procyclical fiscal policy therefore creates an unfavorable trade-off between macroeconomic stabilization and government bond risk premia that is difficult to avoid using standard interest rate policies.

Differences in the cyclicality of fiscal policy have been widely documented in the literature (Lane, 2003; Galí and Perotti, 2003), and evidence of pro-cyclicality in fiscal policy has been uncovered in a number of studies (Gavin and Perotti, 1997; Talvi and Vegh, 2005). However, as pointed out by Leeper (2010), in comparison to the vast literature on monetary rules and on the monetary transmission mechanism, it is fair to say that research on fiscal rules, including the implications of cyclical fiscal policy, has received considerably less attention.

The rest of the paper is organized as follows. Section 2 presents the model and section 3 describes the estimation results. Section 4 discusses the counterfactual policy experiments. Section 5 concludes.

\section{The model}

We present a variant of a NNS model (Goodfriend and King, 1997; Woodford, 2003; Galí, 2008; Smets and Wouters, 2007) where the government collects taxes, issues long-term non-defaultable bonds, uses its proceeds to consume private goods produced by monopolistically competitive firms and makes lump sum transfers to households. Households consume, pay taxes, provide labour for the monopolistic firm, trade oneperiod bonds and invest in long-term bonds issued by the government. Firms hire labour from the households and produce a differentiated good subject to identical technology. Firms price their products subject to a Calvo friction. Monetary and fiscal authorities control the short-term nominal interest rate as well as government consumption, the labour income tax rate and lump-sum transfers, respectively. 


\subsection{Households}

The economy is populated by representative, infinitely-lived households who solve the following dynamic optimisation problem:

$$
\begin{aligned}
& \max _{C_{t}, N_{t}, B_{t}^{S}, B_{t}^{L}} \mathbb{E}_{0} \sum_{t=0}^{\infty} \beta^{t} U\left(C_{t}, X_{t-1}, N_{t}\right) \\
& s . t \\
& \int_{0}^{1} P_{t}(i) C_{t}(i) d i+Q_{t}^{S} B_{t}^{S}+Q_{t}^{L} B_{t}^{L}=\left(1-\mathfrak{t}_{t}\right) W_{t} N_{t}+T R_{t}+B_{t-1}^{S} \\
&+\delta_{c} Q_{t}^{L} B_{t-1}^{L}+B_{t}^{L} \\
& C_{t} \equiv\left(\int C_{t}(i)^{1-\frac{1}{\epsilon_{t}}} d i\right)^{\frac{\epsilon_{t}}{\epsilon_{t}-1}} \\
& X_{t}= m X_{t-1}+(1-m) C_{t} v\left(1-N_{t}\right)
\end{aligned}
$$

where $C_{t}(i)$ is the quantity of good $i$ consumed by the household in period $t ; P_{t}(i)$ is the price of good $i ; N_{t}$ is the quantity of labour; $W_{t}$ is the nominal wage; $B_{t}^{S}$ are nominally riskless one-period bonds (purchased at time $t$ and maturing at date $t+1$ ), with the nominal price $Q_{t}^{S} ; B_{t}^{L}$ are nominally riskless coupon bonds with price $Q_{t}^{L}$ that pay a geometrically decaying coupon in perpetuity, with decay factor $\delta_{c} ; T R_{t}$ is the lump sum component of income (transfers); $\boldsymbol{\epsilon}_{t}$ is the (time-varying) own price elasticity of demand of good $i ; \mathfrak{t}_{t}$ is labour tax rate; $X_{t}$ denotes the habit stock; $m$ is the habit stock parameter; $\beta$ is the discount factor and $U($.$) is a concave and v($.$) is$ a convex function in its arguments and will be specified below. $\mathbb{E}$ is the mathematical expectations operator.

The first-order conditions with respect to bond holdings and consumption give rise 
to the familiar Euler equations

$$
\begin{aligned}
Q_{t}^{S} & =\beta \mathbb{E}_{t}\left\{\frac{U_{C}\left(C_{t+1}, X_{t}, N_{t+1}\right)}{U_{C}\left(C_{t}, X_{t-1}, N_{t}\right)} \frac{P_{t}}{P_{t+1}}\right\} \\
Q_{t}^{L} & =1+\delta_{c} \beta \mathbb{E}_{t}\left\{\frac{U_{C}\left(C_{t+1}, X_{t}, N_{t+1}\right)}{U_{C}\left(C_{t}, X_{t-1}, N_{t}\right)} \frac{P_{t}}{P_{t+1}} Q_{t+1}^{L}\right\}
\end{aligned}
$$

where $U_{C}$ denotes the marginal utility of consumption. Note that $Q_{t}^{S}=\left(1+i_{t}\right)^{-1}$, where $1+i_{t}$ denotes the yield of a one-period discount bond. ${ }^{5}$ The second Euler equation (5) is the pricing formula for government long-term bonds. The optimal choice of labour supply yields the following intratemporal condition:

$$
\frac{\left(1-\mathfrak{t}_{t}\right) W_{t}}{P_{t}}=-\frac{U_{N}\left(C_{t}, X_{t-1}, N_{t}\right)}{U_{C}\left(C_{t}, X_{t-1}, N_{t}\right)}
$$

where $U_{N}$ denotes the marginal disutility of labour. The representative household also decides on the allocation of its consumption expenditures among differentiated goods. This gives rise to the usual demand equation:

$$
C_{t}(i)=\left(\frac{P_{t}(i)}{P_{t}}\right)^{-\epsilon_{t}} C_{t}
$$

where $P_{t} \equiv\left(\int P_{t}(i)^{1-\epsilon_{t}} d i\right)^{\frac{1}{1-\epsilon_{t}}}$ is the aggregate price index, and $C_{t}$ denotes aggregate private consumption.

\subsection{Specification of utility}

We assume that the utility function takes the following form:

$$
U\left(C_{t}, X_{t-1}, N_{t}\right)=\frac{\left(C_{t} v\left(1-N_{t}\right)-b X_{t-1}\right)^{1-\sigma}}{1-\sigma}
$$

where $\sigma$ is the curvature parameter of utility, $C_{t}$ is consumption, $X_{t-1}$ is the predetermined habit stock, and where $v\left(1-N_{t}\right)=\phi+\left(1-N_{t}\right)^{\varsigma}$ satisfies the usual regularity

\footnotetext{
${ }^{5}$ Note that this equations implies that, approximately, $i_{t}=-\log \left(Q_{t}^{S}\right)$.
} 
conditions. ${ }^{6}$ The curvature parameter $\sigma$ is the coefficient of relative risk aversion in the composite good $C_{t} v\left(1-N_{t}\right) .{ }^{7}$ The law of motion of the habit stock $X_{t}$ depends on the composite good $C_{t} v\left(1-N_{t}\right)$, reflecting the key assumption that habits are formed over the aggregate of consumption and leisure. Compared to a standard specification of habit formation (Abel, 1990; Constantinides, 1990; Jermann, 1998; Campbell and Cochrane, 1999), the introduction of leisure provides households with an additional margin which can be used to control the evolution of the habit stock. The habit parameter $m$ controls the rate at which the stock of habits depreciates, while $1-m$ determines the sensitivity of the reference level with respect to changes in the composite good. The second habit parameter $0 \leq b<1$ measures the importance of the habit motive in utility. ${ }^{8}$

Given this specification of utility and assuming internal habit formation, it can then be shown that:

$$
\begin{aligned}
U_{C}\left(C_{t}, X_{t-1}, N_{t}\right)= & \left.\left(C_{t} v\left(1-N_{t}\right)-b X_{t-1}\right)^{-\sigma}\right) v\left(1-N_{t}\right) \\
& +(1-m) v\left(1-N_{t}\right) \varphi_{t}, \\
U_{N}\left(C_{t}, X_{t-1}, N_{t}\right)= & \left.\left(C_{t} v\left(1-N_{t}\right)-b X_{t-1}\right)^{-\sigma}\right) C_{t} v_{N} \\
& +(1-m) \varphi_{t} C_{t} v_{N} .
\end{aligned}
$$

where $\varphi_{t}$ is the Lagrange multiplier associated with the habit accumulation equation and $v_{N}$ is the first derivative of leisure utility with respect to $N$.

\footnotetext{
${ }^{6}$ See King and Rebelo (1999) for a discussion of the regularity conditions. Note that $\phi$ is pinned down by the steady state of the model while $\varsigma$ controls the Frisch elasticity of labor supply.

${ }^{7}$ For further details of this specification of utility, see Jaccard (2010).

${ }^{8}$ Compared to the specification used in Jaccard (2010), we use a specification with $b$ and $m$ allowing for an additional degree of freedom in order to facilitate the estimation procedure. When $b$ is set to zero, the model reduces to a specification without habit formation.
} 


\section{$2.3 \quad$ Firms}

Following the standard New Keynesian setup, we assume that there is a continuum of firms indexed by $i \in[0,1]$. Each firm is owned by the households, produces a differentiated good using a homogenous technology. Firms' production possibilities are given by the production function: $Y_{t}(i)=A_{t} N_{t}(i)^{1-\alpha}$. $A_{t}$ represents the common level of technology that follows an $A R(1)$ process. We assume that capital is fixed at unity. All firms face identical isoelastic demand schedules (7) and take aggregate prices and quantities as given. We make the typical assumption that each firm may re-set its price only with probability $1-\theta$. The average price duration is given by $1 /(1-\theta)$. A firm re-optimizing in period $t$ chooses the price $P_{t}^{*}$ that maximizes the current market value of the profits generated while that price remains effective, $\sum_{k=0}^{\infty} \theta^{k} \mathbb{E}_{t}\left\{\mathfrak{m}_{t, t+k}\left(P_{t}^{*} Y_{t+k \mid t}-\Psi_{t+k}\left(Y_{t+k \mid t}\right)\right\}\right.$ subject to the demand function $Y_{t+k \mid t}=\left(\frac{P_{t}^{*}}{P_{t+k}}\right)^{-\epsilon_{t}} C_{t+k}$, for $k=0,1,2, \ldots$. Note that $\Psi_{t+k}$ is the cost function at time $t+k$ and $Y_{t+k \mid t}$ denotes output in period $t+k$ for a firm that last reset its price in period $t$.

The nominal stochastic discount factor from period $t$ to period $t+k$ is given by

$$
\mathfrak{m}_{t, t+k} \equiv \beta^{k} \frac{U_{C, t+k}}{U_{C, t}} \frac{P_{t}}{P_{t+k}}
$$

The first-order condition can be written as:

$$
\sum_{k=0}^{\infty} \theta^{k} E_{t}\left\{\mathfrak{m}_{t, t+k}\left(Y_{t+k \mid t}\left(\frac{P_{t}^{*}}{P_{t-1}}-\mathcal{M M C}_{t+k \mid t} \Pi_{t-1, t+k}\right)\right)\right\}=0
$$

where $\mathcal{M} \equiv \frac{\bar{\epsilon}}{\bar{\epsilon}-1}$ denotes the steady-state (frictionless) price mark-up and $\Psi_{t+k}^{\prime}\left(Y_{t+k \mid t}\right)$ denotes the marginal cost function at time $t+k$ for the firm that last re-set its price at time $t$. Inflation is defined as $\Pi_{t, t+k} \equiv P_{t+k} / P_{t}$ and $\mathcal{M C}_{t+k \mid t} \equiv \frac{\Psi_{t+k}^{\prime}\left(Y_{t+k \mid t}\right)}{P_{t+k}}$ denotes real marginal costs. Typically, this optimal price setting condition is linearized around the zero inflation steady state (Galí, 2008). However, since we use higher-order approximation, we re-write condition (12) in a recursive form, and use perturbation methods to 
evaluate the recursive form of the first-order condition around the deterministic steady state price level where $\frac{P_{t}^{*}}{P_{t-1}}=1$ and $\Pi_{t-1, t+k}=1$. For details, see Appendix C.

\subsection{Pricing of long-term bonds and risk premium}

The pricing of the assets in this economy is based on the household's valuation of future payoffs of the assets, being it future profit streams of the firms or the payment structure associated with government bonds. Future payoff streams are valued on the basis of the stochastic discount factor introduced in equation (11). Following Rudebusch and Swanson (2008), we have simplified the computational burden associated with the introduction of a 10-year bond by assuming that the government issues longterm, default-free bonds that pay a geometrically declining coupon in every period in perpetuity. Hence, the nominal price of the bond per one dollar of coupon in period $t$ satisfies: ${ }^{9}$

$$
Q_{t}^{L}=1+\delta_{c} \mathbb{E}_{t}\left(\mathfrak{m}_{t, t+1} Q_{t+1}^{L}\right)
$$

where $\delta_{c}$ is the rate of decay of the coupon on the bond and $\mathfrak{m}_{t+1}$ is the (nominal) stochastic discount factor between period $t$ and $t+1 .{ }^{10}$ The decay factor $\delta_{c}$ controls the duration or maturity of the bond. When $\delta_{c} \rightarrow 0$, this bond behaves increasingly like a short-term asset, while higher values of $\delta_{c}$ imply an increasing duration of the bond.

The risk-free (or rather risk neutral) price of the bond is given by

$$
\hat{Q}_{t}^{L}=\mathbb{E}_{t} \sum_{j=0}^{\infty} e^{-i_{t, t+j}} \delta_{c}^{j}=1+\delta_{c} \exp \left(-i_{t}\right) \hat{Q}_{t+1}^{L},
$$

\footnotetext{
${ }^{9}$ The price of a default-free $n$-period zero coupon bond that pays one dollar at maturity satisfies

$$
Q_{t}^{(s)}=\mathbb{E}_{t}\left[\mathfrak{m}_{t, t+1} Q_{t+1}^{(s-1)}\right]=\mathbb{E}_{t}\left(\Pi_{j=1}^{s} \mathfrak{m}_{t, t+j}\right)
$$

where $Q_{t}^{(s)}$ denotes the price of a bond with maturity $s$.

${ }^{10}$ This is essentially the Euler condition for long-term bonds given in equation (5). This is computationally far less burdensome, since pricing of long-term financial claims based on exact Euler equation involves pricing of all the claims up to maturity $L$. Using equation (13) involves only one additional state variable.
} 
where $i_{t, t+j} \equiv \sum_{s=0}^{j} i_{s}$ and the second equality in equation (14) follows from the firstorder expansion of equation (13).

One commonly-used measure of the bond risk premium is based on the difference between the risk adjusted yield-to-maturity and the risk-neutral yield-to-maturity of the bond. ${ }^{11}$ The continuously-compounded yield-to-maturity $\mathfrak{i}_{t}^{L}$ on the bond is given by:

$$
\mathfrak{i}_{t}^{L} \equiv \log \left(\frac{\delta_{c} Q_{t}^{L}}{Q_{t}^{L}-1}\right) .
$$

Correspondingly, the yield of a risk-free bond is given by:

$$
\widehat{\mathfrak{i}}_{t}^{L} \equiv \log \left(\frac{\delta_{c} \hat{Q}_{t}^{L}}{\hat{Q}_{t}^{L}-1}\right)
$$

Hence, the implied bond risk premium is given by:

$$
\psi_{t}^{L} \equiv \mathfrak{i}_{t}^{L}-\widehat{\mathfrak{i}}_{t}^{L}=\log \left(\frac{\delta_{c} Q_{t}^{L}}{Q_{t}^{L}-1}\right)-\log \left(\frac{\delta_{c} \hat{Q}_{t}^{L}}{\hat{Q}_{t}^{L}-1}\right)
$$

Another commonly-used measure of the bond risk premium is based on the excess (realized) one-period holding return $\left(\mathfrak{e}_{t}^{h r}\right)$. The holding-period return on a bond is the return from holding the bond for a single period and selling it before maturity. The excess holding-period return is defined by subtracting the current short-term rate from the relevant expression for the holding-period return. Hence, we get that: ${ }^{12}$

$$
\mathfrak{e}_{t}^{h r}=\frac{\delta_{c} Q_{t}^{L}+e^{i_{t-1}}}{Q_{t-1}^{L}}-e^{i_{t-1}}
$$

In this case, the bond risk premium can be interpreted as a compensation for the risk averse investors for the possible capital loss on a long-term bond if it is sold before maturity and/or the risk due to erosion of the bond's value by inflation.

\footnotetext{
${ }^{11}$ Yield-to-maturity is the constant rate of discount that equates the net present value of future coupon payments with the current market price of the bond.

${ }^{12}$ For zero coupon bonds, the corresponding formula is given by $\mathfrak{e}_{t}^{h r}=Q_{t}^{(L-1)} / Q_{t-1}^{L}-e^{i_{t-1}}$
} 
Note that the unconditional expectation of the bond risk premia based on the measures in equation (18) and (17) are identically, when computed in a second-order approximation. The implied variances of the two measures however, differ with regard to the property that the excess holding return has a non-zero variance, while equation (17) gives a zero variance in a first- or second-order approximation.

The slope of the yield curve is given by the difference between the yield-to-maturity on the long-term bond and the one-period risk-free rate $i_{t}$, i.e. $\mathfrak{s l}_{t}=\mathfrak{i}_{t}^{L}-i_{t} .{ }^{13}$

\subsection{Government}

The government in the economy collects taxes, issues non-defaultable long-term bonds and uses the revenues for government consumption and transfers. There is no seignorage. The government's (nominal) flow budget constraint in this economy can be expressed as:

$$
\begin{aligned}
Q_{t}^{L} B_{t}^{L}+P_{t} S_{t} & =B_{t}^{L}+\delta_{c} Q_{t}^{L} B_{t-1}^{L} \\
S_{t} & =\tau_{t}\left(W_{t} / P_{t}\right) N_{t}-\left(G_{t}+T R_{t}\right),
\end{aligned}
$$

where $S_{t}$ denotes the primary surplus. $\tau_{t}, G_{t}$ and $T R_{t}$ denote the labour income tax rate, government consumption and lump sum net transfers respectively. $B_{t}^{L}$ denotes the dollar value of long-term nominal bonds outstanding and $Q_{t}^{L}$ denotes the nominal price of the bonds sold at time $t$. Note importantly that, in contrast to one-period debt, the nominal value of debt $\left(Q_{t}^{L} B_{t}^{L}\right)$ depends on bond prices, which in turn depend on expected future inflation. Hence, the current nominal value of debt outstanding depends on the expected path of future inflation, and hence on monetary policy. In contrast to the case of a one-period bond, this implies that the nominal value of debt outstanding at time $t$ is not predetermined.

\footnotetext{
${ }^{13}$ For details and discussion on different measures of risk premium, see e.g. Rudebusch and Swanson (2008).
} 
For further use, we define:

$$
\begin{aligned}
S_{Y, t} & \equiv \tau_{t}\left(W_{t} N_{t} / P_{t} Y_{t}\right)-\left(\frac{G_{t}}{Y_{t}}+\frac{T R_{t}}{Y_{t}}\right) \\
& =\tau_{t}\left(W_{t} N_{t} / P_{t} Y_{t}\right)-\left(G_{Y, t}+T R_{Y, t}\right) .
\end{aligned}
$$

as the ratio of the real value of the primary surplus to current output. As for the law of motion of government bonds, we define $B_{P Y, t}^{L} \equiv B_{t}^{L} /\left(Y_{t} P_{t}\right)$ as the ratio of the real value of long-term bonds to output. Then we can express the real government budget constraint as: ${ }^{14}$

$$
Q_{t}^{L} B_{P Y, t}^{L}=B_{P Y, t}^{L}+\delta_{c} \frac{Q_{t}^{L} B_{P Y, t-1}}{\left(Y_{t} / Y_{t-1}\right) \Pi_{t}}-S_{Y, t},
$$

Fiscal policy is characterized by the following feedback equations:

$$
\begin{aligned}
G_{Y, t} & =G_{Y}-\phi_{G Y}\left(\frac{Y_{t}}{\bar{Y}}-1\right)-\phi_{G B}\left(\frac{D_{Y, t-1}}{D_{Y}}-1\right)+\varepsilon_{t}^{G}, \\
\tau_{t} & =\tau+\phi_{\tau Y}\left(\frac{Y_{t}}{\bar{Y}}-1\right)+\phi_{\tau B}\left(\frac{D_{Y, t-1}}{D_{Y}}-1\right)+\varepsilon_{t}^{\tau}, \\
T R_{Y, t} & =T R_{Y}-\phi_{T R Y}\left(\frac{Y_{t}}{\bar{Y}}-1\right)-\phi_{T R B}\left(\frac{D_{Y, t-1}}{D_{Y}}-1\right)+\varepsilon_{t}^{T R} \\
\varepsilon_{t}^{G} & =\rho_{G} \varepsilon_{t-1}^{G}+\eta_{t}^{G}, \eta_{t}^{G} \sim N\left(0, \sigma_{G}^{2}\right) \\
\varepsilon_{t}^{\tau} & =\rho_{\tau} \varepsilon_{t-1}^{\tau}+\eta_{t}^{\tau}, \eta_{t}^{\tau} \sim N\left(0, \sigma_{\tau}^{2}\right) . \\
\varepsilon_{t}^{T R} & =\rho_{T R} \varepsilon_{t-1}^{T R}+\eta_{t}^{T R}, \eta_{t}^{T R} \sim N\left(0, \sigma_{T R}^{2}\right)
\end{aligned}
$$

where $G_{Y}, D_{Y}$ and $\tau$ denote the steady state values of the ratio of government consumption to output, the debt ratio and the labour income tax rate. $\varepsilon^{G}$, $\varepsilon_{t}^{\tau}$ and $\varepsilon_{t}^{T R}$ capture exogenous (autocorrelated) shocks to government spending, labour income taxes and transfers. $\eta_{t}^{G}, \eta_{t}^{\tau}$ and $\eta_{t}^{T R}$ are unexpected (discretionary) changes to government spending, taxes and transfers and $\rho_{j}$ captures the degree of serial correlation of the fiscal

\footnotetext{
${ }^{14}$ Note that $B_{P Y, t}$ and $S_{Y, t}$ are stationary variables such that the steady state version of $(22)$ collapses to $S_{Y}=(1-\beta) D_{Y}, \Pi=1, \Delta Y=1$ where $D_{Y} \equiv \delta_{c} Q^{L} B_{P Y}^{L}$ is the steady state real government debt to output ratio. This follows from the Euler equation (5) which in the steady state with zero inflation and zero growth implies that $1 / Q^{L}=\left(1-\delta_{c} \beta\right)$.
} 
shocks. Parameters $\phi_{j B}$, for $j=G, \tau$ and $T R$ capture the feedback of government spending, taxes and transfers on the government debt to output ratio, while $\phi_{j Y}$ captures the extent to which fiscal policy co-moves with the business cycle, because of automatic stabilizers. In general, these feedback coefficients direct (in a reduced form way) the systematic features of fiscal policy. Note that transfers are lump-sum in our model and have an allocative role only through the "second-round" feedback effects on labour taxes and government spending.

Finally, monetary policy is characterised by the usual interest rate feedback rule, given by

$$
\begin{aligned}
i_{t} & =\rho_{i} i_{t-1}+\left(1-\rho_{i}\right)\left[\log (1 / \beta)+\phi_{\pi}\left(\log \left(\Pi_{t} / \Pi^{*}\right)\right)+\phi_{y}\left(\log \left(Y_{t} / \bar{Y}\right)\right]+\eta_{t}^{i},\right. \\
\eta_{t}^{\mathrm{i}} & \sim N\left(0, \sigma_{\mathfrak{i}}^{2}\right)
\end{aligned}
$$

and where $\rho_{i}$ is the interest rate smoothing coefficient and $\phi_{\pi}$ and $\phi_{y}$ are the usual feedback coefficients on inflation and trend output gap, and $\Pi_{t} \equiv P_{t} / P_{t-1}$. The equilibrium real interest rate in the model is given by $\log (1 / \beta) . \eta_{i, t}$ captures iid shocks to monetary policy.

\subsection{Market Clearing}

There are three markets (goods, labour and bond markets ) that need to be in equilibrium at each point of time. We assume that the household's initial long-term bond holdings are positive such that $Q_{-1}^{L} B_{-1}^{L}>0$, while net holdings of one-period bonds are zero in equilibrium. Market clearing in the goods market requires that at time $t$ : $Y_{t}(i)=C_{t}(i)+G_{t}(i)$ for all $i \in[0,1]$. Assuming that the government decides on the allocation of its expenditures $\left(G_{t}\right)$ among differentiated goods similarly to the household such that $G_{t}(i)=\left(\frac{P_{t}(i)}{P_{t}}\right)^{-\epsilon_{t}} G_{t}$, we obtain that:

$$
Y_{t}(i)=\left(\frac{P_{t}(i)}{P_{t}}\right)^{-\epsilon_{t}} Y_{t}, Y_{t}=C_{t}+G_{t}
$$


The market clearing condition in the labour markets requires that $N_{t}=\int_{0}^{1} N_{t}(i) d i$. Inverting the production function $Y_{t}(i)=A_{t} N_{t}(i)^{1-\alpha}$ and using (30), it follows from the labour market clearing condition that:

$$
N_{t}=\left(\frac{Y_{t}}{A_{t}}\right)^{\frac{1}{1-\alpha}} \Delta_{p, t}, \Delta_{p, t} \equiv \int_{0}^{1}\left(\frac{P_{t}(i)}{P_{t}}\right)^{\frac{-\epsilon_{t}}{1-\alpha}} d i
$$

where $\Delta_{p, t}$ is a measure of price dispersion across firms. Consequently, in the symmetric equilibrium, the aggregate supply condition satisfies $Y_{t}=A_{t}\left(N_{t} \Delta_{p, t}^{-1}\right)^{1-\alpha}$.

See Appendix B for a description of the treatment of the price dispersion term.

\section{Estimation}

The model is estimated using Bayesian full information estimation methods as in An and Schorfheide (2007). For our data sample, we use U.S. quarterly data from 1971Q1 to 2007Q4. As observable variables, we use consumption, inflation, Federal funds rate (short-term nominal interest rate), the government consumption to output ratio, labour income tax revenues and the transfers to output ratio. All quantity variables are linearly de-trended and measured in real terms. Inflation and short-term interest rate are de-meaned and expressed in annualized terms. The detailed description of the construction of the variables is provided in Appendix F. Corresponding to the six observable variables, there are six exogenous shocks: productivity shocks, government spending shocks, labour income tax shocks, transfer shocks, interest rate shocks and mark-up shocks. Except for interest rate shocks, which are assumed to be iid, all other shocks follow a first-order autoregressive process.

We estimate the model using the first-order Taylor approximation around the deterministic steady state, but stochastically simulate the second- respectively third-order Taylor approximation of the model around the non-stochastic steady state in order to 
compute the bond risk premium. ${ }^{15}$

\subsection{Calibrated parameters}

The model is calibrated around a steady state with zero inflation. It is important to note that the risk premium is zero in the deterministic steady state. ${ }^{16}$

Table 1 in Appendix A shows the values assigned to the parameters of the model that are calibrated. In the fiscal block of the model, the key parameters are the government debt to output ratio $D_{Y}$, the government consumption to output ratio $G_{Y}$, lump-sum transfers $T R_{Y}$, and the decay parameter $\delta_{c}$, which controls the maturity of the government bonds. $D_{Y}, G_{Y}$ and $T R_{Y}$ are calibrated using U.S. quarterly data from 1971 until 2007, such that $D_{Y}=0.33, G_{Y}=0.076$ and $T R_{Y}=0.104$. Following Leeper, Plante, and Traum (2010), we target the fiscal variables relevant for the federal government, not the general government. These, together with other parameters of the model, imply that the steady state labour income tax rate $\tau$ is 0.23 and the steady state primary surplus to output ratio $S_{Y}$ is $0.01 .{ }^{17} \delta_{c}$ is set equal to 0.9848 , following Rudebusch and Swanson (2008). This implies a Macaulay duration for the government bond of 10 years (40 quarters). ${ }^{18}$ The discount rate $\beta$ is set to equal 0.997 , which is a standard value used in the literature.

Regarding households, we calibrate $\varsigma$ to 1.66 and $\sigma$ to 1 . We do not attempt to estimate these parameters as they are poorly identified. We choose $\phi$ such that the

\footnotetext{
${ }^{15}$ Estimation and simulations were done using Dynare, available at http://www.dynare.org; Adjemian, Bastani, Juillard, Mihoubi, Perendia, Ratto, and Villemot (2011).

${ }^{16}$ In higher-order approximations the assumption on steady state inflation is not innocuous, see (Ascari and Rossi, 2011). To avoid possible repercussions of the mean of inflation on the determination of the risk premium we calibrate the model around a zero inflation steady state. When estimating the model we bridge the difference between the means implied by data and by the model by suitable measurement equations.

${ }^{17}$ See Appendix $\mathrm{F}$ for exact definitions of the variables and other details of the data.

${ }^{18}$ The Macaulay duration is a measure of the average length of time for which money is invested, where the present values of each coupon payment is used to construct the average. The formula is $D=\sum_{t=1}^{m} \frac{t C_{t}}{\left(1+i_{t}\right)^{t}} / Q$, where $D$ denotes the Macaulay duration of the bond, $m$ is the maturity, $i$ is the yield and $Q$ is the price of the bond. In the case of continuous compounding, the same formulae can be written as $D=\sum_{t=1}^{m} t C_{t} \exp (-i t) / Q$.
} 
representative household devotes $20 \%$ of its time to market activities in the model's steady state. As for the supply side of the model, we set the steady state price markup to $20 \%$. This is achieved by setting the price elasticity of demand $\epsilon$ to 6 in the model's steady state. The production function curvature parameter is set to unity. All remaining parameters are estimated.

Turning to the choice of priors, which are reported in Table 2, on the firm and household side, we set the Calvo parameter to 0.6, implying an average contract duration of 2.5 quarters. The prior on the two habit formation parameter are 0.6 and 0.9. For the interest rate rule we start from a Taylor type rule where the inflation response coefficient is set to 2 and the output response coefficient is set to 0.5 . The interest rate smoothing parameter is set to 0.7 . These are all quite standard calibrations. Concerning the fiscal rules we set the response to debt to 0.03 for taxes and for expenditures and to 0.015 for transfers. We set the prior on the cyclical response coefficient for expenditures to 0.0. A negative coefficient for this parameter implies that fiscal policy is pro-cyclical. All priors on the shock persistence are set to 0.7. The priors on the standard deviations of the innovations are calibrated to roughly reproduce the variances of the observable variables. The remaining parameter values are reported in Table 2.

\subsection{Estimation results}

Table 2 in Appendix A reports the estimation results. The estimation results in the posterior mode column give the value of the structural parameters obtained from the maximized log posterior distribution with respect to the model parameters. The next column gives the respective standard deviations. The second set of results gives the mean, 5th and 95th percentile of the posterior distribution obtained from the Metropolis-Hastings sampling algorithm based on 700,000 draws.

Turning to the parameter estimates we find that most of the parameter estimates are in line with comparable studies. On the household side the sensitivity of habits to 
overall utility $b$ is estimated to be 0.83 implying an important contribution of habit formation to overall utility. The depreciation of the habit level $m$ is estimated to be 0.9 , pointing towards a considerable degree of memory in the habit formation process. The specific form of our utility makes it difficult to compare these estimates directly with previous studies. The estimation of the Calvo parameter implies an average price duration of 9 quarters which is on the high side, but in line with the results of comparable studies. ${ }^{19}$

Turning to the policy rules and starting with the monetary policy rule our estimates are in line with Smets and Wouters (2007). We find a slightly lower response of interest rates to inflation and a higher response to the output level, where it is important to note that Smets and Wouters have an additional term on the change in output.

On the fiscal side the comparison to other studies is less straightforward. The paper by Leeper, Plante, and Traum (2010) is closest to our approach, because they are also relating the fiscal instruments to output and debt and use a comparable dataset for the fiscal variables. The estimated coefficients, however, are not directly comparable because the definitions of the explanatory variables is different. The signs of estimated coefficients are the same in both studies, but we find a stronger role for the cyclical elements.

\section{Fiscal policy, monetary policy, and the bond risk premium}

\subsection{Results and accuracy test}

Table 3 reports some stylized facts of the data underlying the estimation procedure and reports some further financial statistics that do not enter as observable variables

\footnotetext{
${ }^{19}$ Following the proposal by Eichenbaum and Fisher (2007), Smets and Wouters (2007) use a Kimball aggregator to overcome the problem of an overstated price duration estimates in DSGE models. The reduced form estimate of the Phillips Curve coefficients in Smets and Wouters however is close to our estimate.
} 
into the estimation but serve as reference statistics to measure the success of the model to replicate financial data. Focusing on the financial variables (including measures of the bond premium), we observe that the measures of the risk premium based on the difference between the risk adjusted yield-to-maturity and the risk-neutral yield-tomaturity of the bond $\left(\psi_{t}^{40}\right.$, equation 17$)$ is around 106 basis points while the measure based on the excess holding return $\left(\mathfrak{e}_{t}^{h r}\right.$, equation 18) is substantially higher around 176 basis points. The slope of the yield curve is positive, with a mean of around 96 basis points. The standard deviation of the financial variables are on average higher than the standard deviations of the real variables.

To evaluate the empirical relevance of the model, the estimated values of the structural parameters discussed in section 3.2 are used to compute simulated moments, based on a second-order approximation for the main macro variables and third-order approximations for the measures of the risk premium. Table 3 below reports a series of financial market and business cycle moments generated by the model and compares them with the data. Starting from the main macroeconomic variables, the fluctuations of output and consumption, measured by the standard deviations, fall short of the fluctuations observed in the data. Hours worked are more volatile in the model reflecting the lack of an extensive margin of employment adjustment and the high degree of price rigidities in the model. The standard deviations of the fiscal variables in the model are close to those found in the data with the exception of the debt to output ratio, where the model variable displays overstated fluctuations. Turning to the correlations with output, we find that the model matches the high correlation coefficients found in the data for the macroeconomic variables. On the fiscal ratios we find that the correlations with output are more difficult to match. The ratio of government expenditure over output has a positive correlation with output while the data finds a negative relation between the two variables. For the financial variables, the model matches the mean of the variables rather well. We find that the interest rate volatility in the model is only moderately higher than in the data. Inflation volatility is slightly lower in the model 
than in the data.

Turning to the risk premium, we find that the benchmark model is able to generate a mean bond premium, $\psi^{40}$, of 72 basis points without coming at the cost of an overstated variability of the main macro and financial variables. Within this class of models, this seems to constitute a significant improvement. As shown and reviewed by Rudebusch and Swanson (2008), state of the art NNS models with standard specification of habit formation (Christiano, Eichenbaum, and Evans (2005) or Smets and Wouters (2007)) usually find it difficult to generate a bond premium larger than 10 basis points.

\section{[Table 3 to be inserted around here]}

The flexibility of our Bayesian approach allows us to further assess the model's ability to explain the bond premium by taking into account the impact of parameter uncertainty. Figure 1 in Appendix A reports the simulated distribution of the mean bond premium generated by the model.

Compared to the estimated model, switching-off habit formation would lead to a dramatic decline in the bond premium. The chosen preference specification plays a key role in producing a sizeable risk premium in the model economy and opens the door for studying the asset pricing implications of fiscal policy.

The time-variation in bond premium can be studied by simulating the model at posterior mode using a third-order approximation. Compared to the asset pricing literature (Campbell and Cochrane, 1999; Bansal and Yaron, 2004; Cochrane and Piazzesi, 2005; Piazzesi and Schneider, 2007), the advantage of our Bayesian approach is that it also allows us to exploit the information provided by macroeconomic aggregates to decompose these movements. The contribution of macroeconomic shocks can be analyzed, and as shown by Figure 5, technology, government spending, and mark-up shocks are the main drivers of the time-variation in bond premia.

The accuracy of the higher-order approximations have also been checked by performing a series of Euler equation tests. As shown in Table 7, the low mean absolute 
errors that we found indicates that both the second and the third-order approximations are reliable. In situations where the actual series is far from its steady state value, we also find that the third-order approximation performs better than the second-order approximation. ${ }^{20}$

\subsection{What drives the risk premium?}

As illustrated by Table 4 in Appendix A, in this economy, 97 percent of the historical variance of output are explained by technology and government expenditure shocks. Technology shocks are the main driving force and explain more than fifty percent of the total variance of output. Inflation is largely driven by the mark-up shock and the technology shock. Technology shocks and government expenditure shocks also explain most of the variance of marginal utility and bond prices. ${ }^{21}$

The key is that both the government spending and the technology shocks generate a negative co-movement between marginal utility and bond prices. As explained by den Haan (1995), generating this co-movement which implies that bond prices are low in states where marginal utility, or "hunger" is high, is the key challenge. If bond prices are high in states where marginal utility is high, long-term bonds are a hedge against unforeseen movements in consumption and in some cases the bond premium can even be negative (Backus, Gregory, and Zin, 1989).

The model's ability to increase the bond premium essentially relies on the introduction of habit formation in the composite of consumption and leisure (Jaccard, 2010). This specification of habit formation induces a particular consumption smoothing motive which overcomes the difficulties induced by the introduction of endogenous labor supply. The key is that this specification of habit formation reduces fluctuations in the composite good $C_{t} v\left(1-N_{t}\right)$, and at the same time increases the volatility of marginal utility. Greater fluctuations in marginal utility increase the volatility of the stochastic

\footnotetext{
${ }^{20}$ See Figure 4 in Appendix D, lower panel.

${ }^{21}$ The high importance of technology and government spending shocks to explain output and inflation dynamics is also found by Curdia and Reis (2010).
} 
discount factor which in turn lead to larger fluctuations in bond prices. This joint effect on the co-movement of the stochastic discount factor and bond prices enables our NNS model to generate a higher bond risk premium than usually reported. Given the importance of technology and government spending shocks, the remainder of this section focuses on the contribution of these two shocks.

\section{Technology shocks}

As argued above, technology shocks can only contribute to explaining the risk premium if they imply a negative and sizable covariance structure between the stochastic discount factor and bond prices.

Figure 2 shows that in the case of a positive technology shock, prices go down. For standard coefficients in the monetary policy rule, this induces a decline in interest rates leading to an increase in bond prices. Following the rise in bond prices the co-movement described above will only be obtained if marginal utility declines.

In the standard NNS model it is difficult to reproduce a sizeable reduction in marginal utility after a positive technology shock. The standard model does produce a positive response in consumption and a decline in marginal utility. However the decline in hours limits the positive response of private consumption, such that the quantitative response of marginal utility is rather small for reasonable parametrizations. The negative response of hours is due to the price stickiness which forces profit maximizing firms to reduce labour demand in order to take advantage of an increase in total factor productivity. $^{22}$

\section{[Figure 2 to be inserted around here]}

Under our specification of multiplicative preferences, the decline in hours leads to a gradual rise in the composite good, $C_{t} v\left(1-N_{t}\right)$ and in combination with habit

\footnotetext{
${ }^{22}$ In contrast to this, in an RBC model prices adjust instantaneously downward leading firms to increase hiring. As a result, the consumption response (and hence the response of marginal utility) is relatively stronger in the RBC model in comparison to the NNS model.
} 
formation, to a sizable decrease in marginal utility. ${ }^{23}$ Given a high degree of price rigidities the response of hours is relatively large, implying a strong reaction of marginal utility. The strong reduction in labour demand induced by price stickiness leads to a decline in output in the short run. For this specific combination of parameters, as in Basu, Fernald, and Kimball (2006), in the short run, technology shocks can therefore be contractionary in our model.

\section{Government spending shocks}

Adopting a specification of preferences which links the stochastic discount factor to future expected paths of the composite good implies that also government spending shocks contribute to explaining the risk premium.

As in all models with intertemporal optimization an increase in government spending implies a negative wealth effect associated with the expectation of higher future net-taxes. The negative wealth effect implies an increase in labor supply. Furthermore we find that the households increase consumption to compensate for the disutility effects of higher hours worked. ${ }^{24}$

\section{[Figure 3 to be inserted around here]}

The hours response leads to a reduction in current and expected levels of the composite good, $C_{t} v\left(1-N_{t}\right)$, compare Figure 3 . While consumption and output rise, the fact that the increase in government spending forces agents to work harder reduces the composite good and raises marginal utility. Furthermore, the demand induced expansion leads to an increase in inflation and interest rates and consequently to a decline in bond prices.

\footnotetext{
${ }^{23}$ Compare Uhlig (2007) and Campbell and Cochrane (1999) for an analysis habit formation and asset pricing in an RBC context and Rudebusch and Swanson (2008), Ravenna and Seppälä (2007) and Wei (2009) for similar studies in a DSGE context.

${ }^{24}$ The positive response of consumption is due to the non-separability of consumption and leisure in the utility function as discussed in Linnemann (2006). Compared to Rudebusch and Swanson (2011), the positive response of consumption to government spending shocks is an important distinguishing feature of our approach.
} 
Since this mechanism generates a negative co-movement between marginal utility and bond prices in this economy, introducing fiscal policy into the analysis contributes to the resolution of the bond premium puzzle.

\section{Monetary policy shocks}

In our economy, monetary policy shocks have the potential to generate qualitative implications that are consistent with financial market data. As in Wei (2009) however, the size and the persistence of the monetary policy shock that would be needed to have a significant impact on the bond premium is clearly implausible. Deviations from interest rules of such a magnitude are never observed in practice.

\subsection{The role of fiscal and monetary policy}

This section uses the framework described above to assess the impact of fiscal rules on business cycle aggregates and on the bond risk premium. Out of the three fiscal instruments that have been introduced only government consumption $G_{Y, t}$ has significant quantitative implications. Taxes, $\tau_{t}$, have very little effect, and by construction, transfers, $T R_{Y, t}$, have no direct impact on the allocation of resources. Hence, in what follows, we focus on the cyclical properties of government consumption.

\section{Fiscal stabilization}

To assess the quantitative implications of pro-cyclical fiscal policies, we perform a series of counterfactual experiments by varying the sensitivity of government consumption to trend output gap. Compared to the estimated fiscal rules for government consumption, we approximate differences in the degree of pro-cyclicality by varying the coefficient $\phi_{G Y}$ in the fiscal rule:

$$
G_{Y, t}=G_{Y}-\phi_{G Y}\left(\frac{Y_{t}}{\bar{Y}}-1\right)-\phi_{G B}\left(\frac{D_{Y, t-1}}{D_{Y}}-1\right)+\epsilon_{t}^{G}
$$

Compared to the estimated rule $\left(\phi_{G Y}=0.31\right)$, in the first experiment we study 
the consequences of pro-cyclical fiscal policy by setting $\phi_{G Y}$ to -0.20 . One may also interpret this experiment as a variation in the level of automatic stabilization induced by fiscal policy.

The results reported in Table 5 clearly show that fiscal rules can have large quantitative implications. As far as business cycle variables are concerned, more pro-cyclical fiscal policy unambiguously leads to an increase in the volatility of output and inflation. Interestingly, as shown by the last row of Table 5, this increase in business cycle volatility is accompanied by a significant increase in the bond risk premium. Pro-cyclical fiscal policy does not only lead to destabilizing effects on the business cycle but can also lead to a dramatic increase in the bond risk premium. Compared to the estimated rule which features counter-cyclical fiscal policy, the bond risk premium increases from 72 to 202 basis points when fiscal policy becomes moderately pro-cyclical. ${ }^{25}$

\section{[Table 5 to be inserted around here]}

Pro-cyclicality also contributes to worsen the policy trade-off faced by central banks by raising the unconditional mean and the volatility of inflation. As illustrated by the impact on the risk-free rate volatility, the rise in inflation and output volatility induces larger fluctuations in interest rates. Pro-cyclicality in fiscal policy therefore complicates the task of the central bank by making macroeconomic stabilization more difficult to achieve.

Finally, in the last column of Table 5, we consider a case with a higher degree of habit formation than in the benchmark case (0.88 vs. 0.83). With a larger habit formation coefficient, the impact of pro-cyclicality on the risk premium is amplified. Our results therefore suggest that adopting counter-cyclical fiscal policy rules could help to contain the rise in risk premia during periods of high risk aversion. ${ }^{26}$

\footnotetext{
${ }^{25}$ Iara and Wolff (2010) study a similar question from an empirical perspective. Using a fiscal dataset for euro area countries, the authors find that the spread with respect to Germany could be reduced by up to 100 basis points, if weak fiscal rules were to be upgraded, implying a stricter institutional and legal backing for fiscal rules.

${ }^{26}$ This relates to the discussion on the impact of fiscal reforms during the financial crisis. If a deep
} 


\section{Macroeconomic stabilization under pro-cyclical fiscal policy}

To illustrate the consequences of pro-cyclicality, the next policy experiment considers a case where the central bank is committed to deliver price and output stability in an economy where pro-cyclical fiscal policies are run by the government. The dynamics of the benchmark model are reported in column 1 of Table 6. Column 2 of the same table reports a slightly modified version of the model with the only difference of assuming a mildly pro-cyclical fiscal rule by setting $\phi_{G Y}$ to -0.1 .

Column 3 reports the dynamics of the model corresponding to the case where the monetary authority tries to offset the effects of pro-cyclical fiscal policy on output fluctuations by raising the output gap coefficient, $\phi_{y}$. Compared to the benchmark case, $\phi_{y}$ needs to be increased from 0.45 to 5.4 in order to bring the volatility of output back to 0.84. Compared to the case where fiscal policy is counter-cyclical, output stabilization therefore comes at the cost of increasing the bond risk premium from 72 basis points to 484 basis points.

Column 4 shows the impact of a policy response aimed at offsetting the impact of pro-cyclical fiscal policy on the level of inflation. Compared to the benchmark case, raising the inflation coefficient, $\phi_{\pi}$, from 1.83 to 2.83 allows the monetary authority to bring the level of inflation volatility back to 44 basis points. Compared to the case where fiscal policy is counter-cyclical, containing the rise in inflation therefore comes at the cost of increasing the bond premium from 72 basis points to 154 basis points.

\section{[Table 6 to be inserted around here]}

Offsetting the impact of a moderate increase in the pro-cyclicality of government spending requires monetary policy to be more aggressive in order to attain the same degree of price or output stability. While the effects of pro-cyclical fiscal policy on inflation and output can be partially offset, this policy option has the side-effect of increasing the government bond risk premium. Monetary policy activism inevitably

crisis is caused by a strong increase in risk aversion a move towards a counter-cyclical fiscal policy can help to sustain government finances by decreasing the cost of financing via a lower risk premium. 
leads to an increase in interest rate volatility. This volatility is in turn transmitted to the term premium via the term structure of the interest rate and increases the cost of government debt.

\section{Automatic stabilizers and the bond premium}

The previous section focused on the impact of counter-cyclical fiscal policy, or automatic stabilizers, on the risk premium, conditional on the full set of shocks, as estimated in section 3. In this section we look at the role of automatic stabilizers, conditional on a single shock, to evaluate the robustness of our results with respect to the shock identification.

We start with the co-movement generated by a mark-up shock. A negative mark-up shock which makes the economy more efficient has a strong positive impact on output, consumption, and hours worked and leads to a sharp decline in marginal utility. In the presence of fiscal stabilizers, the expansionary impact on output triggers an automatic reduction in government spending which leads to a further decline in marginal utility. This amplifying effect on marginal utility increases the volatility of the stochastic discount factor and leads to an increase in the bond premium.

When technology shocks are the main driving force, fiscal stabilizers unambiguously lead to a decline in both macroeconomic volatility and the bond premium. This result, however, seems to depend on the fact that, in our economy, positive technology shocks do not lead to a strong increase in output. The above discussion on mark-up shocks seems to suggest that a different result could be obtained, should the response of hours worked to technology improvements be positive, as it is the case in real business cycle models. We leave this potentially interesting issue for future work.

Following a positive monetary policy shock, output, consumption, and hours worked go down implying an increase in marginal utility. Bond prices will go down following the increase in interest rates. Automatic stabilizers buffer the reduction of demand and reduce the increase in the bond risk premium.

Finally, in the presence of government spending shocks (i.e. discretionary changes in 
government spending), automatic stabilizers unambiguously lead to a decline in both macroeconomic volatility and the bond premium. This is due to the property that positive spending shocks raise both output and marginal utility. The increase in output triggers a decline in government spending and fiscal stabilizers in this case contribute to reduce fluctuations in marginal utility. These offsetting effects, which then lead to a decline in the stochastic discount factor volatility, give rise to a reduction in the bond premium.

\section{Conclusions}

We find that the standard NNS model with a modified preference specification is capable of reproducing a substantial part of the observed risk premium on government bonds. The internal habit formation based on the composite utility of consumption and leisure induces a substantial negative correlation structure between the stochastic discount factor and the price of government bonds. The negative correlation is based on the strong complementarity of consumption and hours worked as implied by the preferences.

The bond risk premium in our model is largely driven by the technology shock and the government spending shock. Positive technology shocks, as well as contractionary government spending shocks, lead to a reduction in inflation and interest rates and consequently to an increase in bond prices. In both cases, the shocks imply an increase in the utility level derived from the composite good and a reduction in marginal utility of consumption. This cyclical property gives rise to a negative correlation between the stochastic discount factor and bond prices. Hence, bonds do not provide an insurance against consumption risks.

Turning to policy issues, we find that fiscal policy does not only contribute to the risk premium in terms of the discretionary component of fiscal policy but also in terms of its systematic, or rule based, component. More specifically, we find that 
the degree of pro-cyclicality of government spending increases the bond risk premium. This is largely driven by the property that pro-cyclical spending tends to de-stabilize the economy implying an increase in the volatility of bond prices. The model suggests imposing state-contingent fiscal rules with strong counter-cyclical elements. Especially in periods of high risk aversion automatic stabilizers can be used as an instrument to contain risk premia.

Monetary policy can contribute to counteract the destabilizing effects of a procyclical fiscal policy, but only at the cost of an increased risk premium. Pro-cyclical fiscal policy increases the variability of output and inflation. Monetary policy can counteract the increased inflation variability by becoming more aggressive. But when fiscal policy is pro-cyclical, a stronger response of interest rates to inflation increases the bond premium and leads to further increases in the cost of government debt financing. Pro-cyclical fiscal policy creates an unfavorable trade-off between price stability and government bond premia that is difficult to avoid using standard interest rate policies. 


\section{References}

Abel, A. B. (1990): "Asset Prices under Habit Formation and Catching Up with the Joneses," American Economic Review, 80(2), 38-42.

Adjemian, S., H. Bastani, M. Juillard, F. Mihoubi, G. Perendia, M. Ratto, and S. Villemot (2011): "Dynare: Reference Manual, Version 4," Dynare Working Papers, CEPREMAP, 1.

An, S., And F. Schorfheide (2007): "Bayesian Analysis of DSGE Models," Econometric Reviews, 26, 113-172, With discussion, p. 173-219.

Ascari, G., And L. Rossi (2011): "Real Wage Rigidities and Disinflation Dynamics: Calvo vs. Rotemberg Pricing," Economics Letters, 110(2), 126-131.

Backus, D. K., A. W. Gregory, and S. E. Zin (1989): "Risk premiums in the term structure : Evidence from artificial economies," Journal of Monetary Economics, 24(3), 371-399.

Bansal, R., And A. YAron (2004): "Risks for the Long Run: A Potential Resolution of Asset Pricing Puzzles," Journal of Finance, 59(4), 1481-1509.

Basu, S., J. G. Fernald, and M. S. Kimball (2006): “Are Technology Improvements Contractionary?," American Economic Review, 96(5), 1418-1448.

Boldrin, M., L. J. Christiano, and J. D. M. Fisher (2001): "Habit Persistence, Asset Returns, and the Business Cycle," American Economic Review, 91(1), 149166.

Campbell, J. Y., and J. Cochrane (1999): "Force of Habit: A Consumption-Based Explanation of Aggregate Stock Market Behavior," Journal of Political Economy, 107(2), 205-251. 
Christiano, L. J., M. Eichenbaum, and C. L. Evans (2005): "Nominal Rigidities and the Dynamic Effects of a Shock to Monetary Policy," Journal of Political Economy, 113(1), 1-45.

Cochrane, J. H., and M. Piazzesi (2005): "Bond Risk Premia," American Economic Review, 95(1), 138-160.

Constantinides, G. M. (1990): "Habit Formation: A Resolution of the Equity Premium Puzzle," Journal of Political Economy, 98(3), 519-43.

Curdia, V., and R. Reis (2010): "Correlated Disturbances and U.S. Business Cycles," NBER Working Papers, 15774.

De Graeve, F., M. Emiris, and R. Wouters (2009): "A structural decomposition of the US yield curve," Journal of Monetary Economics, 56(4), 545-559.

DEN HAAN, W. J. (1995): "The term structure of interest rates in real and monetary economies," Journal of Economic Dynamics and Control, 19(5-7), 909-940.

Den HaAn, W. J., And A. Marcet (1994): "Accuracy in Simulations," Review of Economic Stucdies, 61(1)), 3-17.

Eichenbaum, M., And J. D. Fisher (2007): "Estimating the frequency of price re-optimization in Calvo-style models," Journal of Monetary Economics, 154(7)), $2032-2047$.

Galí, J. (2008): Monetary Policy, Inflation and the Business Cycle: An Introduction to the New Keynesian Framework. Princeton University Press, Princeton.

Galí, J., J. D. López Salido, and J. Vallés (2007): "Understanding the effects of Government spending on Consumption," Journal of the European Economic Association, 5 (1), 227-270. 
Galí, J., and R. Perotti (2003): "Fiscal policy and monetary integration in Europe," Economic Policy, 18(37), 533-572.

Gavin, M., And R. Perotti (1997): "Fiscal Policy in Latin America," NBER Macroeconomics Annual 1997, Volume 12, NBER Chapters, 11-72.

Goodfriend, M., and R. King (1997): "The New Neoclassical Synthesis and the Role of Monetary Policy," NBER Macroeconomics Annual 1997, 12, 231-296.

Gurkaynak, R. S., B. Sack, and J. H. Wright (2007): "The U.S. Treasury yield curve: 1961 to the present," Journal of Monetary Economics, 54(8), 2291-2304.

Hall, R. E. (2009): "Reconciling Cyclical Movements in the Marginal Value of Time and the Marginal Product of Labor," Journal of Political Economy, 117, 281-323.

Hordahl, P., O. Tristani, and D. Vestin (2008): "The Yield Curve and Macroeconomic Dynamics," Economic Journal, 118(533), 1937-1970.

IARA, A., And G. Wolff (2010): "Rules and risk in the euro area: does rules-based national fiscal governance contain sovereign bond spreads?," European Economy. Economic Papers, 443.

JACCARD, I. (2010): "Asset pricing, habit memory, and the labor market," $E C B$ Working Paper, 1163.

Jermann, U. J. (1998): "Asset pricing in production economies," Journal of Monetary Economics, 41.

Jones, J. (2002): "Has fiscal financing helped stabilize the postwar US economy," Journal of Monetary Economics, 49(4), 709-746.

King, R. G., And S. T. Rebelo (1999): "Resuscitating real business cycles," Handbook of Macroeconomics, in: J. B. Taylor and M. Woodford (ed.), 1(1), 927-1007. 
LAne, P. R. (2003): "The cyclical behaviour of fiscal policy: evidence from the OECD," Journal of Public Economics, 87(12), 2661-2675.

LeEPer, E. (2010): "Monetary Science, Fiscal Alchemy," prepared for Jackson Hole Symposium 2010.

Leeper, E., M. Plante, and N. Traum (2010): "Dynamics of fiscal financing in the U.S.," Journal of Econometrics, 156(2), 304-321.

Linnemann, L. (2006): "The effect of government spending on private consumption: a puzzle?," Journal of Money, Credit, and Banking, 38, 1715-1736.

Monacelli, T., And R. Perotti (2008): "Fiscal Policy, Wealth Effects, and Markups," NBER Working Papers 14584.

Piazzesi, M., And M. Schneider (2007): "Equilibrium Yield Curves," NBER Macroeconomics Annual 2006, Volume 21, pp. 389-472.

Ravenna, F., And J. Seppälä (2007): "Monetary Policy and rejections of the Expectations Hypothesis," mimeo.

Rudebusch, G., And E. Swanson (2011): "The bond premium in a DSGE model with long-run real and nominal risks," Federal Reserve Bank of San Francisco.

Rudebusch, G. D. (2010): "Macro-Finance Models Of Interest Rates And The Economy," Manchester School, 78, 25-52.

Rudebusch, G. D., And E. T. Swanson (2008): "Examining the bond premium puzzle with a DSGE model," Journal of Monetary Economics, 55 (Supplement), S111-S126.

SAntos, M. S. (2000): "Accuracy of numerical solutions using the Euler equation residuals," Econometrica, 68 (6), 1377-1402. 
Smets, F., And R. Wouters (2007): "Shocks and Frictions in US Business Cycles: A Bayesian DSGE Approach," American Economic Review, 97(3), 586-606.

TAlvi, E., And C. A. Vegh (2005): "Tax base variability and procyclical fiscal policy in developing countries," Journal of Development Economics, 78(1), 156-190.

Uhlig, H. (2007): "Explaining Asset Prices with External Habits and Wage Rigidities in a DSGE Model," American Economic Review, 97(2), 239-243.

van Binsbergen, J., J. Fernandez-Villaverde, R. S. Koijen, and J. F. Rubio-RAmirez (2010): "The Term Structure of Interest Rates in a DSGE Model with Recursive Preferences," NBER Working Papers.

WEI, C. (2009): "A quartet of asset pricing models in nominal and real economies," Journal of Economic Dynamics and Control, 33(1), 154-165.

Woodford, M. (2003): Interest and Prices: Foundations of a Theory of Monetary Policy. Princeton University Press, Princeton. 


\section{A Tables and figures}

Table 1: Values assigned to the calibrated parameters

\begin{tabular}{cccccccccc}
\hline & \multicolumn{3}{c}{ FiRms } & \multicolumn{3}{c}{ AND Housenolds } & \multicolumn{4}{c}{ Fiscal PoliCY } \\
\hline \hline$\varsigma$ & 1.66 & $\beta$ & 0.997 & $\bar{\epsilon}$ & 6 & $G_{Y}$ & 0.076 & $D_{Y}$ & 0.33 \\
$\sigma$ & 1 & $\bar{N}$ & 0.20 & $1-\alpha$ & 1 & $T R_{Y}$ & 0.104 & $\delta_{c}$ & 0.9848
\end{tabular}

Note: This table shows the parameter values chosen prior to the estimation procedure and the steady state ratios. Note that the model is calibrated around a zero inflation state. The risk premium in the deterministic steady state is zero. 
Table 2: Parameter estimates

\begin{tabular}{|c|c|c|c|c|c|c|c|c|}
\hline \multirow[t]{2}{*}{ Parameter } & & \multicolumn{3}{|c|}{ Prior } & \multicolumn{4}{|c|}{ Posterior } \\
\hline & & Type & Mean & Std & Mode & Mean & $5 \% C I$ & $95 \% C I$ \\
\hline \multicolumn{9}{|l|}{ FIRMS AND HOUSEHOLDS } \\
\hline Habit formation & $b$ & $\mathcal{B}$ & 0.60 & 0.05 & 0.83 & 0.82 & 0.79 & 0.86 \\
\hline Habit memory & $m$ & $\mathcal{B}$ & 0.90 & 0.01 & 0.90 & 0.90 & 0.88 & 0.92 \\
\hline Calvo & $\theta$ & $\mathcal{B}$ & 0.60 & 0.15 & 0.90 & 0.89 & 0.87 & 0.91 \\
\hline \multicolumn{9}{|l|}{ Fiscal Policy Rules } \\
\hline Exp. resp. to debt & $\phi_{G B}$ & $\mathcal{G}$ & 0.03 & 0.02 & 0.006 & 0.009 & 0.001 & 0.016 \\
\hline Exp. resp. to output & $\phi_{G Y}$ & $\mathcal{N}$ & 0.00 & 0.50 & 0.310 & 0.341 & 0.220 & 0.462 \\
\hline Tax resp. to debt & $\phi_{\boldsymbol{\tau} B}$ & $\mathcal{G}$ & 0.03 & 0.02 & 0.055 & 0.057 & 0.044 & 0.070 \\
\hline Tax resp. to output & $\phi_{\tau Y}$ & $\mathcal{G}$ & 0.01 & 0.005 & 0.006 & 0.008 & 0.002 & 0.015 \\
\hline Transfer resp. to debt & $\phi_{T R I}$ & $\mathcal{G}$ & 0.015 & 0.010 & 0.003 & 0.004 & 0.0004 & 0.008 \\
\hline Transfer resp. to output & $\phi_{T R Y}$ & $\mathcal{N}$ & 0.30 & 0.2 & 0.059 & 0.067 & -0.004 & 0.1369 \\
\hline \multicolumn{9}{|l|}{ INTEREST RATE RULE } \\
\hline Interest rate smoothing & $\rho_{i}$ & $\mathcal{B}$ & 0.70 & 0.15 & 0.89 & 0.885 & 0.86 & 0.91 \\
\hline Resp. to output & $\phi_{x}$ & $\mathcal{G}$ & 0.50 & 0.10 & 0.45 & 0.45 & 0.32 & 0.58 \\
\hline Resp. to inflation & $\phi_{\pi}$ & $\mathcal{G}$ & 2.00 & 0.20 & 1.83 & 1.85 & 1.57 & 2.13 \\
\hline \multicolumn{9}{|l|}{ SHOCK PERSISTENCE } \\
\hline Technology shock & $\rho_{a}$ & $\mathcal{B}$ & 0.70 & 0.15 & 0.976 & 0.967 & 0.947 & 0.986 \\
\hline Mark-up shock & $\rho_{\pi}$ & $\mathcal{B}$ & 0.70 & 0.15 & 0.771 & 0.769 & 0.712 & 0.827 \\
\hline Expenditure shock & $\rho_{G}$ & $\mathcal{B}$ & 0.70 & 0.15 & 0.912 & 0.909 & 0.868 & 0.95 \\
\hline Tax shock & $\rho_{\tau}$ & $\mathcal{B}$ & 0.70 & 0.15 & 0.945 & 0.942 & 0.904 & 0.984 \\
\hline Transfer shock & $\rho_{T R Y}$ & $\mathcal{B}$ & 0.70 & 0.15 & 0.821 & 0.820 & 0.741 & 0.899 \\
\hline \multicolumn{9}{|l|}{ STANDARD DEVIATIONS } \\
\hline Technology shock & $\sigma_{a}$ & $\mathcal{G}^{-1}$ & 0.01 & 0.01 & 0.0081 & 0.0079 & 0.0063 & 0.0094 \\
\hline Mark-up shock & $\sigma_{\pi}$ & $\mathcal{G}^{-1}$ & 1.00 & 0.10 & 0.9930 & 0.9970 & 0.8160 & 1.1720 \\
\hline Interest Rate shock & $\sigma_{i}$ & $\mathcal{G}^{-1}$ & 0.002 & 0.002 & 0.0025 & 0.0026 & 0.0023 & 0.0028 \\
\hline Expenditure shock & $\sigma_{G}$ & $\mathcal{G}^{-1}$ & 0.005 & 0.004 & 0.0031 & 0.0032 & 0.0027 & 0.0038 \\
\hline Tax shock & $\sigma_{\tau}$ & $\mathcal{G}^{-1}$ & 0.005 & 0.004 & 0.0033 & 0.0035 & 0.0031 & 0.0039 \\
\hline Transfer shock & $\sigma_{T R}$ & $\mathcal{G}^{-1}$ & 0.005 & 0.004 & 0.0032 & 0.0032 & 0.0029 & 0.0035 \\
\hline
\end{tabular}

Note: $\mathcal{B}, \mathcal{G}$ and $\mathcal{G}^{-1}$ correspond to Beta, Gamma and inverse Gamma distributions. Posterior densities were computed by creating a sample of 700'000 draws with initial burning sample of 105'000 draws. Average acceptance rate of the chain was roughly $25 \%$. The estimation sample is 1971Q1-2007Q4. 
Table 3: Stylized facts of the estimated model

Business Cycle Statistics

\begin{tabular}{ccccc}
\hline \hline & \multicolumn{2}{c}{ Standard } & \multicolumn{2}{c}{ Correlation } \\
& Deviation $\left(\sigma_{X}\right)$ & \multicolumn{2}{c}{ with output $\left(\rho_{X, Y}\right)$} \\
\hline & Data & Model & Data & Model \\
$\log Y_{t}$ & 1.60 & 0.84 & 1 & 1 \\
$\log C_{t}$ & 1.27 & 0.87 & 0.90 & 0.93 \\
$\log N_{t}$ & 1.24 & 1.76 & 0.80 & 0.91 \\
$G_{t} / Y_{t}$ & 0.24 & 0.30 & -0.59 & 0.09 \\
$T R_{t} / Y_{t}$ & 0.40 & 0.39 & -0.63 & -0.09 \\
$D_{t} / Y_{t}$ & 1.05 & 2.79 & -0.03 & -0.72 \\
$T a x L_{t} / Y_{t}$ & 0.33 & 0.51 & 0.08 & 0.16
\end{tabular}

Financial Statistics

\begin{tabular}{|c|c|c|c|c|}
\hline & \multicolumn{2}{|c|}{ Mean } & \multicolumn{2}{|c|}{ "Std. Deviation } \\
\hline & Data & Model & Data & Model \\
\hline$r_{t}$ & 2.51 & 0.76 & 2.66 & 3.51 \\
\hline$\pi_{t}$ & 4.04 & 0.44 & 2.62 & 2.71 \\
\hline$i_{t}^{40}-i_{t}$ & 0.96 & 0.22 & 1.77 & 3.57 \\
\hline \multicolumn{5}{|c|}{ Bond Risk Premium } \\
\hline & \multicolumn{2}{|c|}{ Mean } & \multicolumn{2}{|c|}{ "Std. Deviation } \\
\hline & Data & Model & Data & Model \\
\hline$\psi_{t}^{40}$ & 1.06 & 0.72 & 0.54 & 0.08 \\
\hline $\mathfrak{e}_{t}^{h r}$ & 1.76 & 0.71 & 23.43 & 9.92 \\
\hline
\end{tabular}

Note: This table compares the implication of the estimated model with a series of business cycle and asset pricing stylized facts. Business cycle statistics are expressed in logs and have been HP-filtered, $\sigma_{X}$ denotes the standard deviation of the variable under study while $\rho_{X, Y}$ denotes its correlation with output. As far as financial statistics are concerned, the mean and the standard deviation have been expressed in annualized percent and the stylized facts for the bond premium are taken from Rudebusch and Swanson (2008). The model implied moments are based on a secondorder approximation around the steady state, except for $\psi_{t}^{40}$ where we resort to a third-order approximation to capture the time-variation in bond premium. 
Table 4: Historical variance decomposition for output, inflation, marginal utility and bond prices.

Historical variance decomposition

\begin{tabular}{cccccc}
\hline \hline & Tech. & Gov. exp. & Mon. pol. & Mark-up & Other \\
& $\left(A_{t}\right)$ & $\left(G_{t}\right)$ & $\left(i_{t}\right)$ & $\left(\epsilon_{t} /\left(\epsilon_{t}-1\right)\right)$ & $\left(\tau_{t}\right),\left(T R_{Y, t}\right)$ \\
\hline $\log Y_{t}$ & 55.9 & 40.9 & 1.8 & 1.3 & 0.1 \\
$\Pi_{t}$ & 14.4 & 0.2 & 0.1 & 84.9 & 0.4 \\
$\log U_{C t}$ & 69.1 & 10.2 & 12.7 & 7.9 & 0.1 \\
$\log Q_{t}^{L}$ & 76.5 & 6.1 & 6.7 & 10.6 & 0.1
\end{tabular}

Note: This table shows the forecast error variance decomposition of the estimated model. Shocks to transfers have a negligible impact on the dynamics of the variables and their contributions is therefore omitted in this table.

Table 5: Sensitivity to alternative specifications of the fiscal rules

\begin{tabular}{ccccc} 
& & & Benchmark Habit, $b=0.83$ & High Habit, $b=0.88$ \\
\hline \hline & Data & Estimated & Pro-cyclical & Pro-cyclical \\
\hline$\phi_{G Y}$ & - & 0.31 & -0.2 & -0.2 \\
$\operatorname{std}\left(\log Y_{t}\right)$ & 1.60 & 0.84 & 3.57 & 5.04 \\
$\operatorname{std}\left(\pi_{t}\right)$ & 2.62 & 2.71 & 2.88 & 3.35 \\
$\operatorname{std}\left(i_{t}\right)$ & 3.41 & 4.70 & 7.57 & 11.7 \\
Mean $\left(\psi_{t}^{40}\right)$ & $\mathbf{1 . 0 6}$ & $\mathbf{0 . 7 2}$ & $\mathbf{2 . 0 2}$ & $\mathbf{5 . 2 8}$
\end{tabular}

Note: This table displays results from counterfactual experiments in the model by varying the degree of cyclical response of government spending on output $\left(\phi_{G Y}\right)$. Business cycle statistics are expressed in logs and have been HP-filtered, std and Mean denotes the standard deviation and unconditional mean of the respective variable. The mean and the standard deviation of financial variables are expressed in annualized percent. 
Figure 1: Density of the bond premium

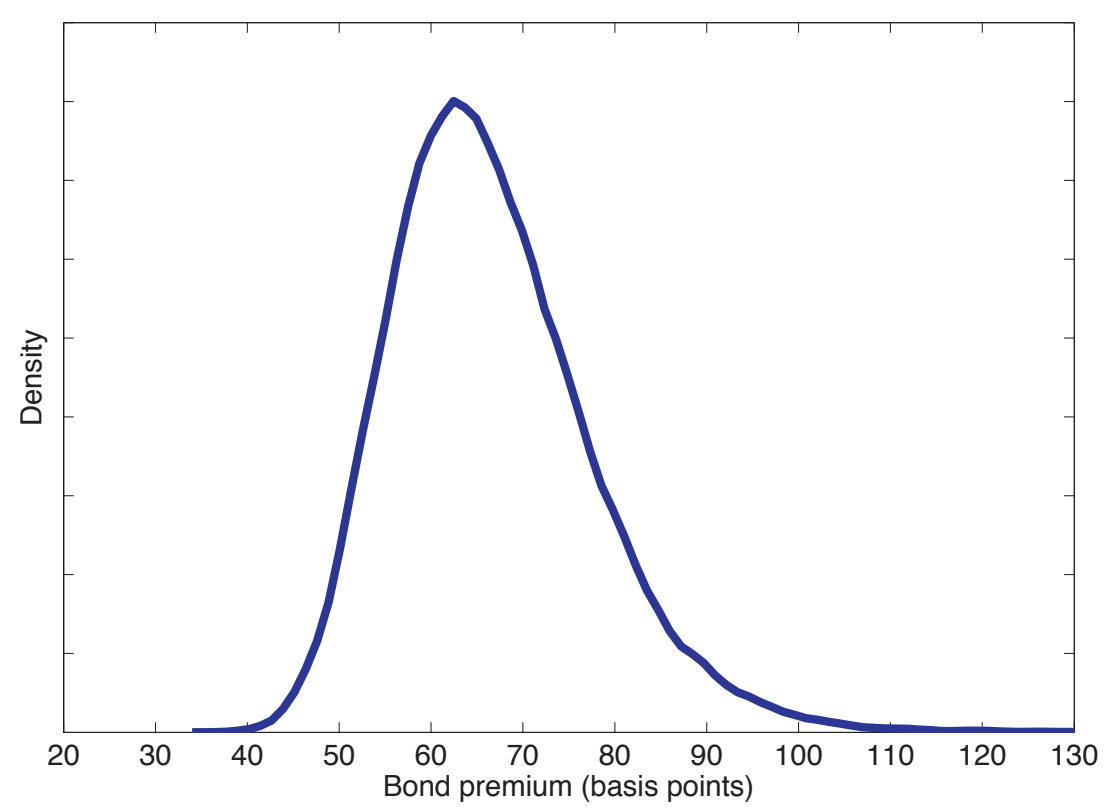

Note: Annualized basis points of the risk premium (equation 17). The simulated distribution has been constructed using the posterior distribution of the estimated parameters given in Table 2. 
Figure 2: Response to technology shock
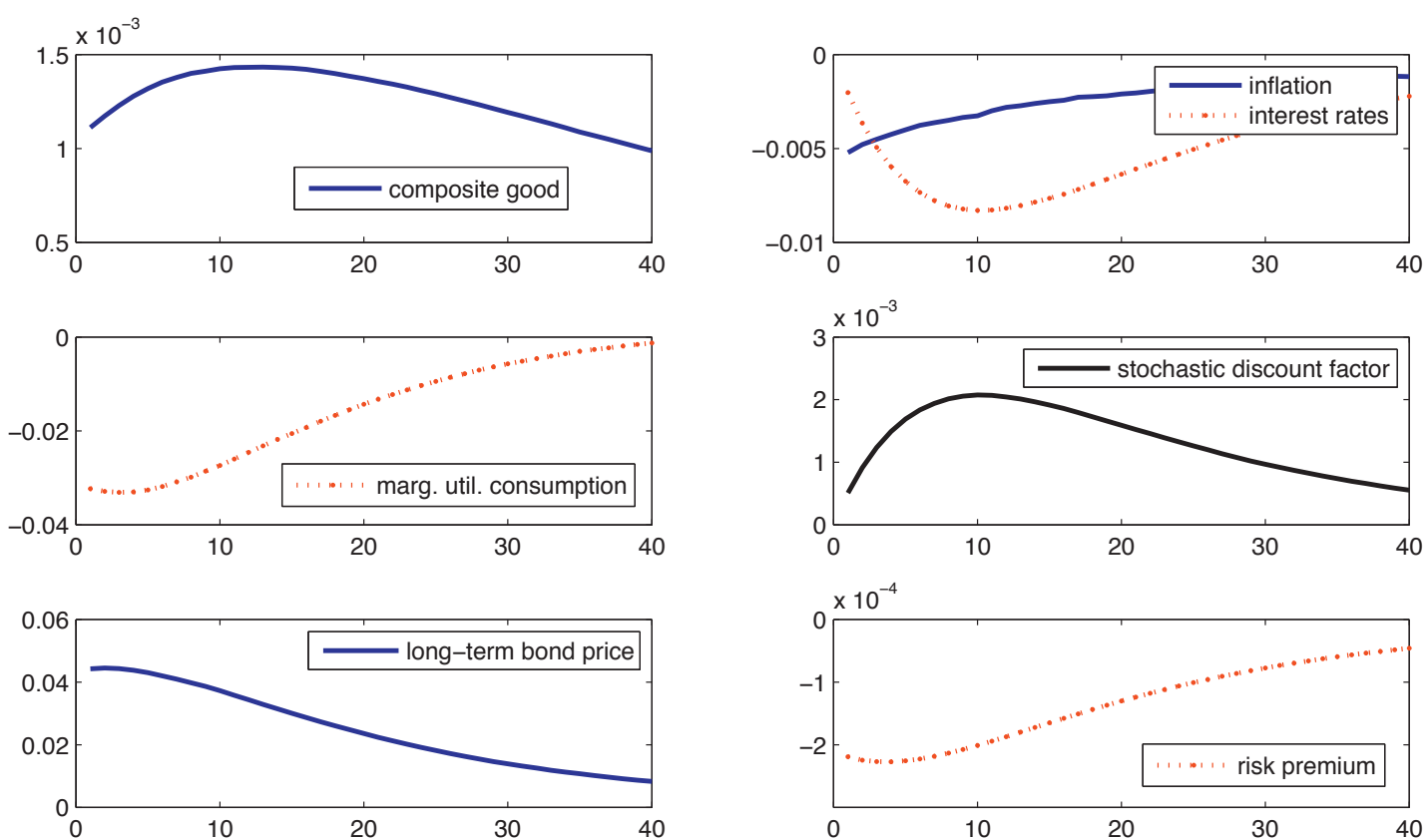

Note: This figure displays the response of selected variables to a positive technology shock. 
Figure 3: Response to government spending shock
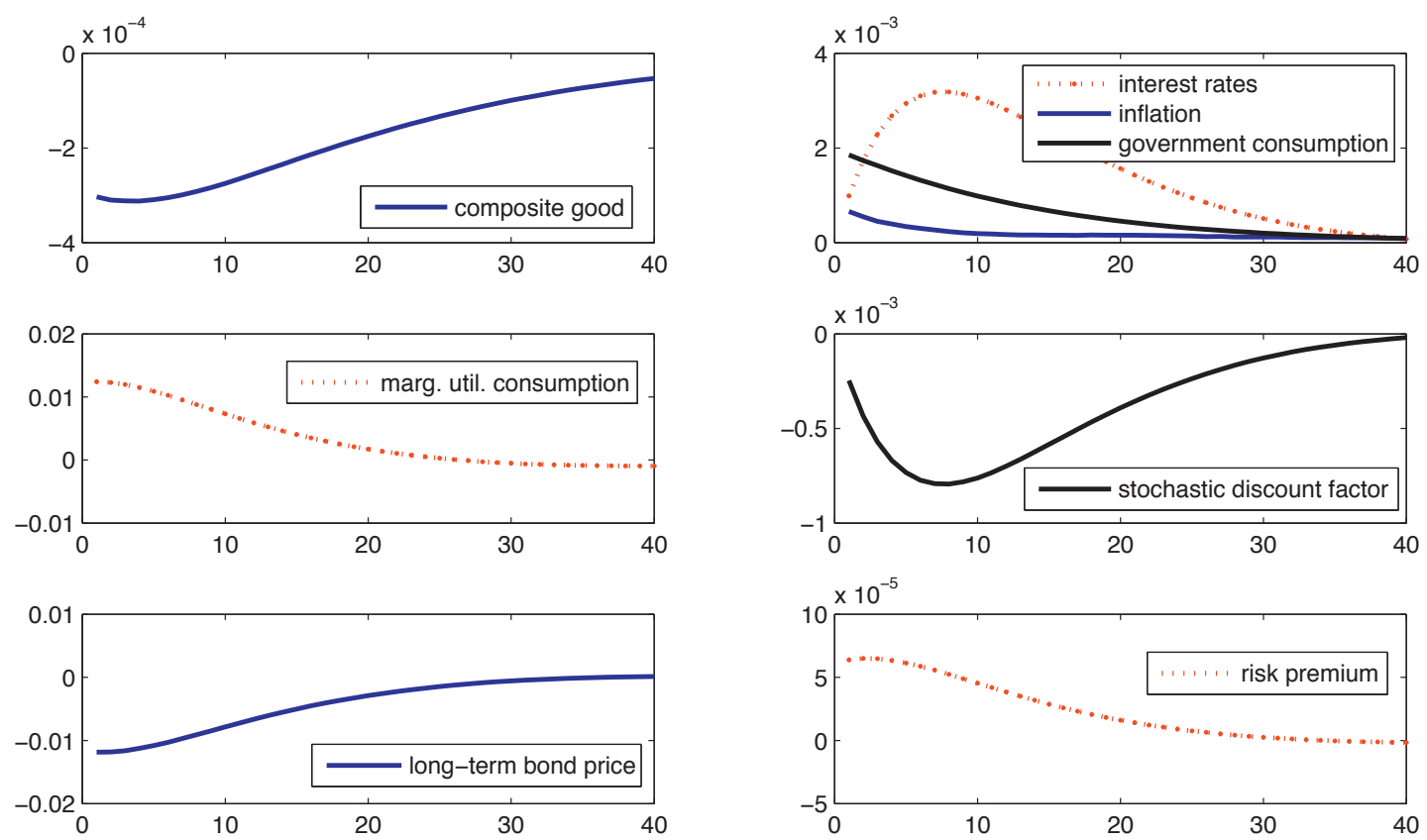

Note: This figure displays the response of selected variables to a positive government spending shock. 
Table 6: Fiscal and monetary policy interaction

\begin{tabular}{|c|c|c|c|c|}
\hline & Benchmark & & Counterfactual & \\
\hline & & & Pro-cyclical & \\
\hline & Benchmark & & Fiscal Policy & \\
\hline & Monetary and & Baseline & Output & Inflation \\
\hline & Fiscal Policy (1) & Mon. Policy (2) & Stabilization (3) & Stabilization (4) \\
\hline$\phi_{\pi}$ & 1.83 & 1.83 & 1.83 & 2.83 \\
\hline$\phi_{y}$ & 0.45 & 0.45 & 5.4 & 0.45 \\
\hline$\phi_{G Y}$ & 0.31 & -0.1 & -0.1 & -0.1 \\
\hline $\operatorname{std}\left(\log Y_{t}\right)$ & 0.84 & 2.10 & 0.84 & 1.99 \\
\hline $\operatorname{std}\left(\pi_{t}\right)$ & 2.71 & 2.81 & 2.83 & 2.60 \\
\hline Mean $\left(\pi_{t}\right)$ & 0.44 & 0.56 & 0.66 & 0.44 \\
\hline $\operatorname{std}\left(i_{t}\right)$ & 4.70 & 6.16 & 11.75 & 6.5 \\
\hline Mean $\left(\psi_{t}^{40}\right)$ & 0.72 & 1.34 & 4.84 & 1.54 \\
\hline
\end{tabular}

Note: This table displays results from counterfactual experiments in the model by varying the degree of cyclical response of government spending on output $\left(\phi_{G Y}\right)$ and the degree of inflation stabilisation $\left(\phi_{\pi}\right)$ in the fiscal and monetary policy rules. Business cycle statistics are expressed in logs and have been HP-filtered, std and Mean denotes the standard deviation and unconditional mean of the respective variable. The mean and the standard deviation of financial variables are expressed in annualized percent. 


\section{B Price dispersion and real marginal costs}

The price dispersion term is small up to the first-order approximation (see e.g. Gali, 2008), so it is usually dropped from the log linear approximation of the aggregate production function. However, since we work on higher-order approximations, we define:

$$
\begin{aligned}
\Delta_{P, t} & =\left(\frac{1}{P_{t}}\right)^{\frac{-\epsilon_{t}}{1-\alpha}} \int_{0}^{1} P_{t}(i)^{\frac{-\epsilon_{t}}{1-\alpha}} d i \\
& =\theta \Pi_{t}^{\frac{\epsilon_{t}}{1-\alpha}}+(1-\theta)\left(\frac{P_{t}^{*} / P_{t-1}}{\Pi_{t}}\right)^{\frac{-\epsilon_{t}}{1-\alpha}},
\end{aligned}
$$

where $\Pi_{t}^{1-\epsilon_{t}}=\theta+(1-\theta)\left(\frac{P_{t}^{*}}{P_{t-1}}\right)^{1-\epsilon_{t}}$ gives the evolution of aggregate inflation dynamics. In the non-stochastic steady state, $\Delta_{P, t}=1$ under the assumption that price level is constant in the steady state (for details, see Galí, 2008, chapter 3).

The equilibrium also entails the derivation of an individual firm's marginal cost in terms of the economy's average real marginal cost to be used in the evaluation of optimal price setting condition (12). It can be shown that $\mathcal{M C}_{t+k \mid t}=\left(\frac{P_{t}^{*}}{P_{t+k}}\right)^{-\frac{\epsilon_{t}}{1-\alpha}} \mathcal{M C}_{t+k}$ and where $\mathcal{M C}_{t+k}$ denotes the economy's average real marginal cost, defined as:

$$
\mathcal{M C}_{t+k} \equiv \frac{W_{t+k} / P_{t+k}}{M P N_{t+k}}
$$

$M P N_{t+k}$ denotes the economy's average marginal productivity of labor and the real wage $W_{t+k} / P_{t+k}$ is evaluated according to the intratemporal condition from the household's problem (6). 


\section{Dynamic model equations}

Recursive representation of the optimal pricing equation:

$$
\begin{aligned}
z_{t}^{N} & =\mathcal{M C} Y_{t} \Pi_{t}^{\frac{(1+\epsilon)}{1-\alpha}}+\theta \beta \mathbb{E}_{t} \frac{U_{C, t+1}}{U_{C, t}} \Pi_{t}^{-1} z_{t+1}^{N} \\
z_{t}^{D} & =Y_{t} \Pi_{t}^{\epsilon}+\theta \beta \mathbb{E}_{t} \frac{U_{c, t+1}}{U_{c, t}} \Pi_{t}^{-1} z_{t+1}^{D} \\
\left(\Pi_{t}^{*}\right)^{1-\epsilon+\frac{\epsilon}{1-\alpha}} & =z_{t}^{N N} / z_{t}^{D} \\
\Pi_{t}^{1-\epsilon} & =\theta+(1-\theta)\left(\Pi_{t}^{*}\right)^{1-\epsilon} \\
z_{t}^{N N} & =\mathcal{M} z_{t}^{N}
\end{aligned}
$$

Price dispersion:

$$
\Delta_{p, t}=\theta \Pi_{t}^{\frac{\epsilon}{1-\alpha}}+(1-\theta)\left(\frac{\Pi_{t}^{*}}{\Pi_{t}}\right)^{-\frac{\epsilon}{1-\alpha}}
$$

Short-term bond pricing equation:

$$
Q_{t}^{S}=\beta \mathbb{E}_{t} \frac{U_{c, t+1}}{U_{c, t}} \Pi_{t}^{-1}
$$

Yield of short-term bond:

$$
i_{t}=-\log \left(Q_{t}^{S}\right)
$$

Marginal utility of consumption:

$$
\begin{aligned}
U_{C, t}= & \left.\left(C_{t}\left(\phi+\left(1-N_{t}\right)^{\varsigma}\right)-b X_{t-1}\right)\right)^{-\sigma}\left(\phi+\left(1-N_{t}\right)^{\varsigma}\right) \\
& +(1-m)\left(\phi+\left(1-N_{t}\right)^{\varsigma}\right) \varphi_{t}
\end{aligned}
$$

Evolution of habit stock:

$$
X_{t}=m X_{t-1}+(1-m) C_{t}\left(\phi+\left(1-N_{t}\right)^{\varsigma}\right)
$$


Evolution of Lagrange multiplier associated to habit stock:

$$
\varphi_{t}=m \beta \mathbb{E}_{t} \varphi_{t+1}-b \beta \mathbb{E}_{t}\left(C_{t+1}\left(\phi+\left(1-N_{t+1}\right)^{\varsigma}\right)-b X_{t}\right)^{-\sigma}
$$

Intratemporal condition:

$$
\begin{aligned}
\left(1-\mathfrak{t}_{t}\right) U_{C, t} w_{t}= & \left(C_{t}\left(\phi+\left(1-N_{t}\right)^{\varsigma}\right)-b X_{t-1}\right)^{-\sigma} \\
& \left(\varsigma C_{t}\left(1-N_{t}\right)^{\varsigma-1}\right) \\
& +(1-m) \varphi_{t} C_{t} \varsigma\left(1-N_{t}\right)^{\varsigma-1}
\end{aligned}
$$

Economy wide real marginal costs:

$$
\mathcal{M C}_{t}=w_{t} /\left((1-\alpha) Y_{t} / N_{t}\right)
$$

Long-term bond pricing equations (risk neutral price and risk adjusted price):

$$
\begin{aligned}
\hat{Q}_{t}^{L} & =1+\mathbb{E}_{t}\left(\delta_{c} \hat{Q}_{t+1}^{L} / \exp \left(i_{t}\right)\right) \\
Q_{t}^{L} & =1+\delta_{c} \beta \mathbb{E}_{t}\left(\frac{U_{C, t+1}}{U_{C, t}} \Pi_{t+1}^{-1} Q_{t+1}^{L}\right)
\end{aligned}
$$

Long-term bond yields (risk neutral yield and risk adjusted yield):

$$
\begin{aligned}
\widehat{\mathfrak{i}}_{t}^{L} & =\log \left(\delta_{c} \hat{Q}_{t}^{L} /\left(\hat{Q}_{t}^{L}-1\right)\right) \\
\mathfrak{i}_{t}^{L} & =\log \left(\delta_{c} Q_{t}^{L} /\left(Q_{t}^{L}-1\right)\right)
\end{aligned}
$$

Bond premium:

$$
\psi_{t}^{L} \equiv \mathfrak{i}_{t}^{L}-\widehat{\mathfrak{i}}_{t}^{L}
$$

Slope of the yield curve:

$$
\mathfrak{s l}_{t}=\mathfrak{i}_{t}^{L}-i_{t}
$$


Excess holding return:

$$
\mathfrak{e}_{t}^{h r}=\left(\delta_{c} Q_{t}^{L}+\exp \left(i_{t-1}\right)\right) / Q_{t-1}^{L}-\exp \left(i_{t-1}\right)
$$

Government real budget constraint:

$$
Q_{t}^{L} B_{P Y, t}=B_{P Y, t}+\delta_{c} Q_{t}^{L} B_{P Y, t-1} \Pi_{t}^{-1}\left(Y_{t} / Y_{t-1}\right)^{-1}-S_{Y, t}
$$

Primary surplus to output ratio:

$$
S_{Y, t}=(1-\alpha) \tau_{t} M C_{t}-G_{Y, t}-T R_{Y, t}
$$

Aggregate output:

$$
Y_{t}=\exp \left(A_{t}\right)\left(N_{t} / \Delta_{p, t}\right)^{1-\alpha}
$$

Consumption to output ratio:

$$
C_{Y, t}=1-G_{Y, t}
$$

Consumption:

$$
C_{t}=C_{Y, t} Y_{t}
$$

Fiscal rules (Government consumption, labour income tax rate, lump-sum transfers):

$$
\begin{aligned}
G_{Y, t} & =G_{Y}-\phi_{G Y}\left(\frac{Y_{t}}{\bar{Y}}-1\right)-\phi_{G B}\left(\frac{D_{Y, t-1}}{D_{Y}}-1\right)+\epsilon_{t}^{G} \\
\tau_{t} & =\tau+\phi_{\tau Y}\left(\frac{Y_{t}}{\bar{Y}}-1\right)+\phi_{\tau B}\left(\frac{D_{Y, t-1}}{D_{Y}}-1\right)+\epsilon_{t}^{\tau} \\
T R_{Y, t} & =T R_{Y}-\phi_{T R Y}\left(\frac{Y_{t}}{\bar{Y}}-1\right)-\phi_{T R B}\left(\frac{D_{Y, t-1}}{D_{Y}}-1\right)+\epsilon_{t}^{T R}
\end{aligned}
$$


Real value of government debt outstanding:

$$
D_{Y, t}=\delta_{c} Q_{t}^{L} B_{P Y, t}
$$

Exogenous shocks procesess:

$$
\begin{aligned}
A_{t} & =\left(1-\rho_{A}\right) \log (\bar{A})+\rho_{A} A_{t-1}+\eta_{t}^{A}, \eta_{t}^{G} \sim N\left(0, \sigma_{A}^{2}\right) \\
\epsilon_{t}^{G} & =\rho_{G} \epsilon_{t-1}^{G}+\eta_{t}^{G}, \eta_{t}^{G} \sim N\left(0, \sigma_{G}^{2}\right) \\
\epsilon_{t}^{\tau} & =\rho_{\tau} \epsilon_{t-1}^{\tau}+\eta_{t}^{\tau}, \eta_{t}^{\tau} \sim N\left(0, \sigma_{\tau}^{2}\right) . \\
\epsilon_{t}^{T R} & =\rho_{T R} \epsilon_{t-1}^{T R}+\eta_{t}^{T R}, \eta_{t}^{T R} \sim N\left(0, \sigma_{T R}^{2}\right) \\
\epsilon_{t} & =\bar{\epsilon}+\rho_{\tau} \epsilon_{t-1}+\eta_{t} \sim N\left(0, \sigma_{\pi}^{2}\right) \\
\epsilon_{t}^{i} & \sim N\left(0, \sigma_{i}^{2}\right)
\end{aligned}
$$




\section{Accuracy of the higher-order approximations}

To evaluate the bond price and the implied risk-premium we have to utilize higher-order perturbation methods. The use of these methods leads to the question how accurate the approximations actually are. In order to evaluate the accuracy we report results from a dynamic Euler equation test below. The basic idea of the Euler equation test is to compare the value provided by the approximation with the exact value derived from the Euler equation, where expectations are approximated by numerical integration. ${ }^{27}$ Since the main focus of the non-linear part of the model refers to the evaluation of the bond risk-premium we report the accuracy results of the long-term bond pricing equation which is the main driver of the risk premium.

$$
Q_{t}^{L}=1+\delta_{c} \beta \mathbb{E}_{t}\left\{\frac{U_{C}\left(C_{t+1}, X_{t}, N_{t+1}\right)}{U_{C}\left(C_{t}, X_{t-1}, N_{t}\right)} \frac{P_{t}}{P_{t+1}} Q_{t+1}^{L}\right\}
$$

To evaluate the Euler equation we first take all period $t$ variables from the approximation. All expectational terms in the equation are then approximated by numerical integration.

Table 7: Properties of the dynamic Euler equation errors (in percent)

\begin{tabular}{ccccc}
\hline \hline & $\begin{array}{c}\text { mean absolute } \\
\text { error }\end{array}$ & $\begin{array}{c}\text { mean } \\
\text { error }\end{array}$ & $\begin{array}{c}\text { max. positive } \\
\text { error }\end{array}$ & $\begin{array}{c}\text { max. negative } \\
\text { error }\end{array}$ \\
\hline 2nd-order & 0.39 & -0.38 & 0.11 & -1.77 \\
3rd-order & 0.19 & -0.19 & 0.11 & -0.67
\end{tabular}

Note: This table shows selected properties of the Euler equation errors (in percent) based on the long-term bond prices. They are based on 2000 simulated data points, using 500 draws for the Monte-Carlo numerical integration.

The fact that the mean absolute errors of both approximations are rather low shows

\footnotetext{
${ }^{27}$ Compare den Haan and Marcet (1994) and Santos (2000) for assessing accuracy based on Euler Equation Residuals.
} 
that both the second and the third-order approximations are reliable. The errors of the second-order approximation (blue dash-dotted line in figure 4) become larger when the variables drift far away from the stochastic steady state. ${ }^{28}$ In these situations the third-order approximation (green solid line in figure 4) performs considerably better.

\footnotetext{
${ }^{28}$ In the stochastic steady state the long-term bond price has a mean of 55.37.
} 
Figure 4: Euler Equation Accuracy: second- and third-order approximation
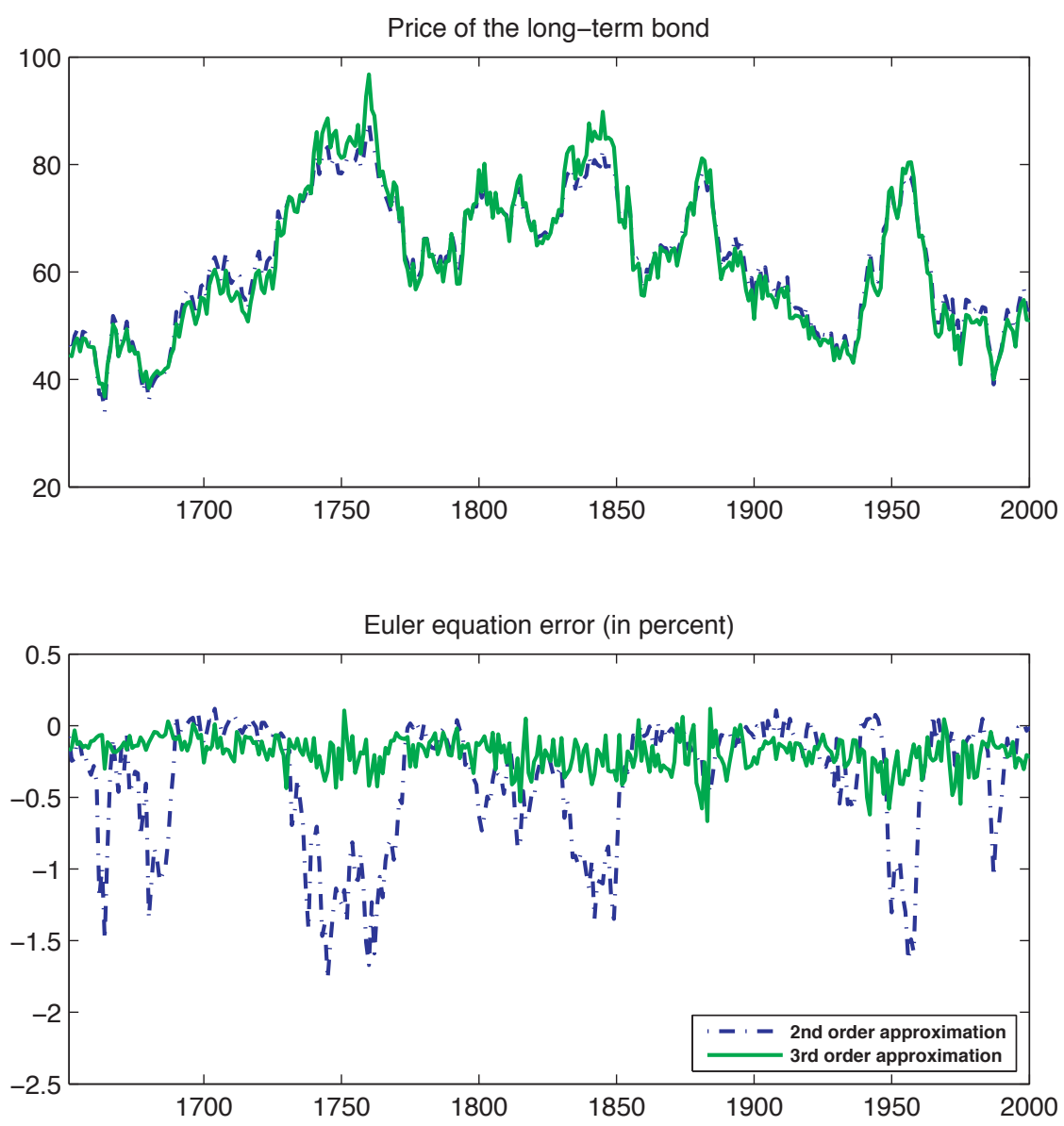

Note: The upper panel of this graph shows the simulated time series for the price of long-term bonds based on the 2nd-order (blue, dash-dotted line) and 3rd order approximations (green, solid line). In the lower panel the approximation error in percent for the 2nd- and 3rd-order are shown. Approximation errors are calculated as the difference between the approximated bond price and the corresponding value of the bond price that would make the Euler equation to hold exactly. The sample window is chosen to contain the maximum error in the second-order approximation. 


\section{E Time variation in the bond premium}

Figure 5: Time variation in the bond premium

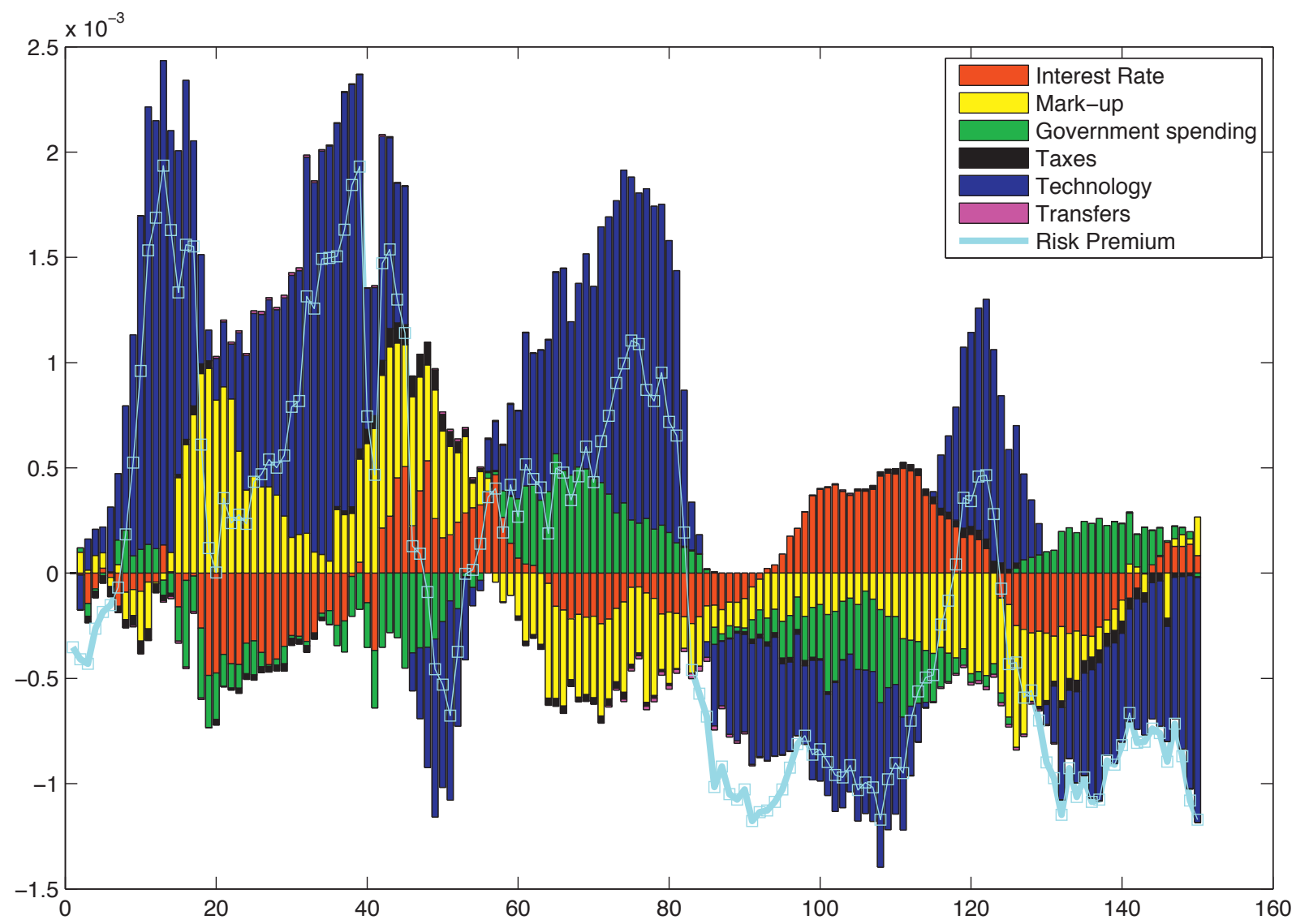

Note: This graph shows the contribution of the shocks to variations of the bond risk premium around its stochastic steady state. Note that each shock also contributes to the size of the mean of the risk premium in the stochastic steady state. For expositional clarity this effect is not displayed in the graph. 


\section{F Construction of data}

We explain the construction of data set in detail. Our approach follows Leeper, Plante, and Traum (2010) for fiscal variables, Hall (2009) for hours, and Gurkaynak, Sack, and Wright (2007) for bond yields. Our complete dataset covers years 1955-2009, but the model is parameterized and estimated using the period 1971Q1-2007Q4.

PY: Gross Domestic Product. Source: Bureau of Economic Analysis (BEA), Nipa Table 1.1.5, line 1.

P: GDP deflator for personal consumption expenditures. Source: BEA, Nipa Table 1.1.4, line 2 .

C: Private consumption. Source: Bureau of Economic Analysis, Nipa Table 1.1.6, line 2

$N$ : Hours, measure of labour input. This is computed as $N=H \times(1-U / 100)$, where $H$ and $U$ are the average over monthly series of hours and unemployment. Source: Bureau of Labour Statistics, series LNU02033120 for hours and LNS14000000 for unemployment.

INT: Net interest payments of federal government debt. Source: Bureau of Economic Analysis, Nipa Table 3.2, (line 29-line 13).

M: Adjusted Monetary Base. Source. ST. Louis Database, series AMBSL.

G: Government consumption. This is computed as $\mathrm{G}=$ current consumption expenditures (line 21) + gross government investment (line 42) + net purchases of nonproduced assets (line 44)-consumption of fixed capital (line 45). Source: BEA, Nipa Table 3.2.

TR: Net transfers. This is computed as TR = net current transfers (line 22-line 16) + net capital transfers (line 43-line 39) + subsidies (line 32)- current surplus of government enterprises (line 19). Source: BEA, Nipa Table 3.2.

TAXR: Total federal tax revenues. This is computed as TAXR = current tax receipts (line 2)+contributions for government social insurance (line 11). Source: BEA, 
Nipa Table 3.2.

$S$ : Primary surplus. This is computed as $S_{t}=T A X R_{t}-\left(G_{t}+T R_{t}\right)$, where $G_{t}$ is government consumption, $T R_{t}$ are net transfers and $T A X R_{t}$ are total federal tax revenues.

$D$ : Federal government debt. This is computed as $D_{t}=D_{t-1}+I N T_{t}-S_{t}-$ $\left(M_{t}-M_{t-1}\right)$, where $S_{t}$ is primary surplus $I N T_{t}$ are net interest payments of federal government debt and $M_{t}-M_{t-1}$ is seignorage. The initial value of debt is set equal to the market value of Gross Federal Debt in March 1955. Source: BEA, Nipa Table 3.2 and http://www.dallasfed.org/data/data/natdebt.tab.htm for the initial value of debt.

$W N_{t}$ : Labour income tax base. Source: Nipa Table 1.12, line 3.

$\tau$ : Average effective labour income tax rate. Computed following Jones (2002) and Leeper, Plante, and Traum (2010).

$L T A X R$ : Labour tax revenues. This is computed as $L T A X R_{t}=\tau_{t} \times W N_{t}$, where $W N_{t}$ denotes labour income tax base (Nipa Table, 1.12, line 3 ) and $\tau_{t}$ is effective labour income tax rate.

$i$ : Federal funds effective rate. Quarterly average over monthly series. Source: Board of Governors of the Federal System, H.15. Selected Interest rates, Series RIFSPFF_N.M.

$\mathfrak{i}_{t}^{L}$ : 10-Year Treasury Constant Maturity Rate. Source: Board of Governors of the Federal Reserve System, Series ID:GS10.

$\mathfrak{e}_{t}^{h r}$ : Excess holding return. Taken from Rudebusch and Swanson (2008).

$\psi_{t}^{L}$ : Bond risk premium. Taken from Rudebusch and Swanson (2008). 
